\title{
De Santiago de Chile a Graz, Austria: la correspondencia entre Rodolfo Lenz y Hugo Schuchardt
}

\author{
Johannes Mücke \\ Universität Graz, Austria \\ Silvio Moreira de Sousa ${ }^{2}$ \\ Macau University of Science and Technology, China
}

\begin{abstract}
Resumen
Esta contribución es el producto del trabajo llevado adelante por los autores para el proyecto "Red de conocimiento" (financiado por el Fondo Austriaco para la Ciencia, FWF 2012-2016, proyecto número P 24400-G15, elaborado, presentado y dirigido por Bernhard Hurch), de la Universidad de Graz, Austria. Si bien el proyecto financiado ya ha concluido, el trabajo en el archivo de Hugo Schuchardt continúa (véase la página web del Hugo Schuchardt Archiv). Este artículo, resultante de la fusión de tres artículos relacionados con el proyecto, procura poner de manifiesto la importancia para la historiografía
\end{abstract}

\footnotetext{
1 Para correspondencia, dirigirse a: Johannes Mücke (johannes.muecke@googlemail. com).

2 Para correspondencia, dirigirse a: Silvio Moreira de Sousa (amdssilvio@must.edu.mo), Macau University of Science and Technology, University International College, Avenida Wai Long, 999078 Macau.
} 
lingüística de estudiar los contactos entre estudiosos. La primera parte proporciona información acerca de Hugo Schuchardt (1842-1927) y Rodolfo Lenz (1863-1938), seguida de una breve introducción al proyecto "Red de conocimiento" y el Archivo Hugo Schuchardt, así como una breve contextualización historiográfica (cf. Hurch 2009a, 2009b, 2009c). La segunda parte del artículo se ocupa del intercambio epistolar entre Lenz y Schuchardt. Aparte de una breve descripción de la correspondencia dentro del Archivo Lenz, se aportan comentarios con respecto a las cartas y el acuerdo teórico entre ambos autores con respecto a las lenguas criollas. La tercera parte de esta contribución contiene la transcripción de la correspondencia entre Lenz y Schuchardt, junto con su traducción al español, realizada por Juan Ennis.

Palabras clave: Hugo Schuchardt, Rodolfo Lenz, Lenguas criollas, Historia de la lingüística.

\title{
From Santiago de Chile to Graz, Austria: THE CORRESPONDENCE BETWEEN RODOLFO LENZ AND Hugo SCHUCHARDT
}

\begin{abstract}
This contribution is product of the work conducted by the authors for the Project "Network of Knowledge" (financed by the Austrian Science Fund FWF 2012-2016, project number P 24400-G15, elaborated, proposed and directed by Bernhard Hurch), at the University of Graz, Austria. Even though the financed project has already concluded, the working on the archive of Hugo Schuchardt continues (see the website Hugo Schuchardt Archiv). This paper, resulting of the fusion of three articles of both authors related to the project, intents to show the importance of studying the contacts between scholars for the history of linguistics. The first part gives some background information about Hugo Schuchardt (1842-1927) and Rodolfo Lenz (1863-1938), followed by a brief introduction of the project "Network of Knowledge" and the Hugo Schuchardt Archive and a short historiographical contexualization (cf. Hurch 2009a, 2009b, 2009c). The second part of the article deals with the letter exchange between Lenz and Schuchardt. Besides a short description of the correspondence inside the Archivo Lenz, comments will be made in regard to the letters and to the theoretical agreement between both authors in respect to the creole languages. The third part of this contribution contains the transcribed correspondence of Lenz and Schuchardt together with a translation into Spanish by Juan Ennis.
\end{abstract}


Keywords: Hugo Schuchardt, Rodolfo Lenz, Creole Languages, History of Linguistics.

Recibido: $15 / 05 / 19$

Aceptado: 29/06/20

\section{INTRODUCCIÓN}

Esta contribución es producto del trabajo de los autores en el proyecto Network of Knowledge (financiado por el Fondo Austriaco para las Ciencias FWF 2012-2016, proyecto $\mathrm{N}^{\circ} \mathrm{P}$ 24400-G15, elaborado, propuesto y dirigido por Bernhard Hurch) en la Universidad de Graz, Austria. Pese al hecho de que el financiamiento ha terminado, los trabajos aún prosiguen (cf. el proyecto de website Hugo Schuchardt Archiv)3. Este capítulo, que resulta de la fusión de tres artículos de ambos autores relacionados con el proyecto, procura demostrar la importancia de un estudio más profundo de los papeles de los académicos ${ }^{4}$. En un primer momento, se introduce el proyecto Network of Knowledge, ofreciendo una descripción sumaria del Archivo Hugo Schuchardt (HSA), junto con una breve contextualización de los desarrollos en la comunicación en el siglo XIX, así como un comentario acerca del contexto de los abordajes historiográficos (y sus conexiones mutuas) a los papeles de los académicos (cf. los textos fundamentales de Bernhard Hurch como el proyecto de investigación para el FWF Network of Knowledge y Hurch 2009a, 2009b, 2009c). La segunda parte de este capítulo está dedicada al intercambio epistolar entre Rodolfo Lenz (1863-1938) y Hugo Schuchardt (1842-1927). Además de una breve descripción de la correspondencia dentro del Archivo Lenz, se ofrecen algunos comentarios acerca de las cartas y el acuerdo teórico entre ambos autores con respecto a las lenguas criollas. En la tercera parte de esta contribución, se dan a conocer las cartas con las convenciones editoriales utilizadas.

\footnotetext{
3 Disponible online en http://schuchardt.uni-graz.at (Hurch 2007-).

4 Los tres artículos en los cuales se basa esta contribución son Mücke y Sousa (2015a), (2015b) y Sousa y Mücke (2016). Partes de esta contribución se basan en una presentación realizada por Bernhard Hurch y Johannes Mücke en la $13^{\text {th }}$ International Conference of the History of the Language Sciences (ICHoLS), que tuviera lugar en 2014 en Vila Real, Portugal.

Quisiéramos expresar nuestro agradecimiento a nuestros antiguos colegas de Graz, así como a James McElvenny por sus comentarios sobre versiones previas de este artículo, y a Juan Ennis por la traducción del texto al español.
} 


\section{HUGO SCHUCHARDT Y SU RED DE CONOCIMIENTO}

\subsection{TRASFONDO HISTÓRICO}

En el siglo XIX, el volumen del correo postal circulante aumentó exponencialmente. Las condiciones de posibilidad para ello tienen que ver no solo con desarrollos técnicos y de infraestructura -tal como la red ferroviaria a través de Europa, el sistema global de líneas de vapores o el creciente número de buzones públicos de correo- sino también con innovaciones de índole organizativa, como por ejemplo el desarrollo del franqueo postal, que va desde la primera estampilla en el sentido moderno en 1840 (One Penny Black en Gran Bretaña) hasta la fundación de la World Postal Union en 1874 (como General Postal Union) en Berna, que estableció las reglas para un servicio postal internacional. La red mundial del servicio postal hizo posible el movimiento global de bienes, capital y conocimiento (cf. para mayor detalle Hurch 2009a, Melchior y Mücke 2013).

Un creciente número de nuevas revistas académicas podría bien ser, simultáneamente, la causa y consecuencia del creciente uso de nuevas tecnologías en la impresión de publicaciones periódicas, lo que hacía posible la producción de un mayor número de copias y un ritmo de publicación acelerado. Además, el nuevo proceso para la producción a partir de la pulpa de celulosa, que logró hacer del papel un objeto de producción masiva, también contribuyó a este resultado (cf. Hurch 2009a, 2009b). En este contexto, investigadores y editores se convirtieron en socios en la misma empresa. Se podría decir que este fue un Gründerzeit -una "era de fundadores"- en las modernas ciencias del lenguaje. Hay toda una generación de investigadores, en su mayoría nacidos alrededor de la década de 1840 o después, que establecieron publicaciones periódicas a partir de los 1860 . Nombres como los de Gaston Paris y Paul Meyer (que fundó Romania en 1872), Graziadio Ascoli (Archivio Glottologico Italiano, 1872), Adalbert Bezzenberger (Beiträge zu Kunde der Indogermanischen Sprachen o los Beiträge de Bezzenberger, 1877) o Gustav Gröber (Zeitschrift für romanische Philologie o Gröbers Zeitschrift, 1877) representan un fenómeno europeo que afectó a todas las disciplinas de las ciencias del lenguaje (Tagliavini 1968: 132-135). Todos estos editores-fundadores estaban en contacto epistolar más o menos frecuente con Schuchardt, como lo estaba Rodolfo Lenz. 


\subsection{Hugo Schuchardt y Rodolfo Lenz}

Ya se cuenta con una buena cantidad de información bibliográfica acerca de ambos autores (cf. Dannemann 2000-2001, Hurch 2007, 2007-, Maas 2010), por lo que no vamos a redundar en demasiados detalles aquí. Rodolfo (Rudolf) Lenz, que había estudiado en Bonn y Berlín, fue contratado por el gobierno de Chile como profesor en el Instituto Pedagógico y en ese sentido formó parte del movimiento migratorio alemán hacia Chile en el siglo XIX. Poco después de su llegada a Chile en 1890, Lenz comenzó con su investigación sobre la lengua y la cultura del pueblo mapuche. En su viaje de vacaciones en 1921, Lenz entró en contacto con el papiamento, una lengua criolla de base ibérica hablada en Aruba, Bonaire y Curazao, lo que sucedió a causa de una parada intermedia en su travesía de Santiago a Hamburgo. Si bien este (Lenz 1926-1927, 1928) resulta menos conocido que otros trabajos suyos (Escudero 1963: 464), Kramer (2004: 38) documenta cuatro reseñas y un libro acerca de su monografía sobre el papiamento: Gillet (1930), Wagner (1931), Hesseling (1933), Seifert (1933) y Maduro (1967). Labarías y Cárdenas (1998: 38-39) mencionan otras dos reseñas (Costa Álvarez 1928, Nyk1 1928) y sabemos que hay otras aún por encontrar (por ejemplo, Wallensköld 1929). Un repaso de la obra de Rodolfo Lenz permite hacerse una impresión de sus posiciones teóricas en el ámbito de la lingüística -tenía una formación sólida en la disciplina tal como se practicaba en Alemania- y dar una explicación del alcance de sus trabajos acerca de las lenguas amerindias, bajo la influencia de su vida en Chile (cf. Bachmann 2004: 380, Ennis 2012).

En cuanto a Hugo Schuchardt, "el padre de la creolística" (Markey 1982: 204), estudió en Jena y Bonn. Entre 1873 y 1876 se desempeñó como Profesor de Filología Románica en Halle y en 1876 tomó a su cargo la cátedra de Filología Románica en la Universidad de Graz. Se retiró en 1900, a pesar de lo cual su investigación prosiguió hasta el momento de su muerte, en 1927. Schuchardt legó su extensa biblioteca (Weiss 1986b) y miles de páginas manuscritas a la Universidad de Graz (Wolf 1993). Solo su correspondencia, recibida prácticamente desde todas partes del mundo, reúne aproximadamente 14000 cartas (ibíd.). Su colección de objetos etnográficos se encuentra preservada en el Volkskundemuseum de Viena (Schwägerl-Melchior 2016). 


\subsection{El archivo Hugo Schuchardt en Graz}

El proyecto "Networks of Knowledge" (2012-2016, financiado por la FWF, proyecto número P 24400-G15, investigador responsable: Bernhard Hurch) tenía como objetivo la presentación online, en acceso abierto, y consecuente análisis de los papeles de Hugo Schuchardt, combinando la edición digital facsimilar de todas sus publicaciones con la edición también digital de su correspondencia, además de una bibliografía de literatura secundaria (Hurch 2007-).

El análisis combinado de estas fuentes proporciona un medio para reconstruir la red científica desplegada a lo largo de la segunda mitad del siglo XIX en las ciencias del lenguaje, sobre las líneas que permite trazar la siguiente hipótesis (Hurch 2009a, 2009b, 2009c): las innovaciones acaecidas en los medios (de comunicación) del siglo XIX, como a) la formación de un sistema global moderno de servicios postales y b) la creación de compañías de impresión y edición modernas, a la que siguió la fundación de publicaciones científicas periódicas, están interrelacionadas con los cambios en las ciencias del lenguaje, como por ejemplo, con la apertura de nuevos campos de investigación, el establecimiento de nuevas prácticas discursivas en el campo científico, nuevas formas de obtener conocimientos, y una diferenciación de las disciplinas científicas, que va de la mano con su institucionalización en las universidades y sociedades científicas.

\subsection{APROXIMACIONES HISTORIOGRÁFICAS}

Hay dos acercamientos posibles para una investigación historiográfica de las relaciones entre estos desarrollos. Por un lado, tenemos el acceso clásico, cuantitativo o hermenéutico de la interpretación del contenido de las fuentes, por ejemplo, los datos lingüísticos, las referencias bibliográficas que contienen, o bien si presentan polémicas, comentarios, descripciones de conclusiones erróneas. Por otro lado, hay un modo cuantitativo o estadístico de aproximación a la investigación de metadatos, que encuentra un ámbito de uso frecuente en las humanidades digitales. Los metadatos no mienten: el hecho de que una carta haya sido enviada por una persona a otra en un momento determinado es un hecho histórico claramente diverso del contenido de la carta. Haciendo uso de ambos métodos en los papeles de Hugo Schuchardt, se puede dar con fuertes argumentos a favor de la hipótesis bosquejada más arriba. 
Un ejemplo del método cuantitativo: el 12 de septiembre de 1886 , Schuchardt le escribió a Otto Jespersen, luego de haber leído y reseñado positivamente un artículo del lingüista danés (Jespersen 1886) en el Deutsche Litteraturzeitung (Schuchardt 1886). Jespersen le había preguntado a Schuchardt si le parecería bien que se hiciera una traducción al alemán del mismo, a lo que Schuchardt no solo respondió positivamente, sino que además le recomendaba una revista que lograría una circulación más amplia y una mayor recepción, junto con otra que no contaba con ningún neogramático entre sus fundadores-editores. Por lo demás, Schuchardt subrayaba que el tiempo era un factor clave, puesto que todo nuevo desarrollo en el debate en curso entre los neogramáticos y sus críticos era objeto de una constante puesta al día, prácticamente cada mes de 1886 (Hurch y Constantini 2007). Finalmente, la traducción (Jespersen 1887) fue publicada en 1887 en la Internationale Zeitschrift für allgemeine Sprachwissenschaft (o "Techmers Zeitschrift").

Haciendo uso del método cuantitativo, es posible proporcionar información estructural acerca de los contactos de Schuchardt con las publicaciones científicas de su época. Schuchardt mantenía correspondencia con una gran cantidad de estos editores-fundadores, en cuyas publicaciones contribuía con mucha frecuencia, como por ejemplo con Gröber (160 cartas recibidas, 288 artículos y 9 reseñas en el "Gröber's Zeitschrift"), y donde sus trabajos eran reseñados habitualmente (12 reseñas). Otro argumento a favor de la conexión entre comunicación, publicación y recepción es el hecho de que Schuchardt no recibía muchas cartas de aquellos editores-fundadores en cuyas revistas no publicaba. Del mismo modo, Schuchardt tampoco recibía muchas reseñas en esas mismas publicaciones. Si bien esto resulta a primera vista bastante obvio, hay señales de algunas anomalías: Schuchardt sostuvo un amplio intercambio epistolar con Gaston Paris (98 cartas recibidas), pero solo publicó 9 artículos en Romania -a pesar de haber recibido reseñas de sus trabajos en 19 ocasiones en esa revista. Más aún, a pesar de haber existido un intenso contacto epistolar entre Schuchardt y Ascoli (139 cartas recibidas; cf. Lichem y Würdinger 2013), Schuchardt no publicó nunca en el Archivio Glottologico Italiano, ni recibió ninguna reseña de sus trabajos allí. Pero tanto Paris como Ascoli eran parte de la red de conocimiento de Schuchardt: al comparar los inventarios epistolares, puede establecerse el hecho de que Ascoli y Schuchardt tienen 130 corresponsales en común y Paris y Schuchardt la nada desdeñable cantidad de 175.

Todo esto tuvo como resultado una amplia variedad de nuevos modos de referencia específicos. Si por un lado hay una mezcla de formas textuales, por el otro hay también una fusión de las mismas: con mucha frecuencia el discurso científico no está limitado a una forma específica, sino que continúa 
a través de toda una variedad de medios de comunicación (cartas, reseñas, réplicas, postscripta, etc.). Algunas discusiones alternan entre diferentes formas de discurso (cf. Hurch 2011, Hurch y Purgay 2015 para el caso de la correspondencia de Schuchardt y von der Gabelentz, o Mücke 2015a para la correspondencia entre Schuchardt y Hermann Paul). Otro fenómeno que observamos es la amalgama de formas textuales: de qué modo los límites entre lo público y lo privado se ven difuminados. Pueden encontrarse diversas formas textuales de transición: publicaciones científicas en forma de cartas, cartas publicadas como ensayos científicos, cartas abiertas, cartas al editor o inclusive dedicatorias personales (Hurch 2009b).

Otro elemento que contribuye a sostener la idea de que la red de las ciencias del lenguaje hacia el cambio de siglos era ciertamente internacional, es el comité asesor de las diversas publicaciones periódicas. Ascoli, Coelho, Gabelentz, Lepsius, Pott o Miklosich, todos ellos eran parte del consejo asesor de del Techmer's Zeitschrift, y de todos encontramos cartas en el legado de Schuchardt (Sousa 2013; Mücke 2015b y Hurch y Melchior 2015). Pero también -lo que no es menos importante- todos ellos estaban en contacto postal entre sí.

\section{EL TENDIDO DE REDES Y SUS OBSTÁCULOS ${ }^{6}$}

\subsection{El Archivo Lenz, Santiago de Chile}

Mientras las cartas de Lenz a Schuchardt fueron de fácil acceso para los autores de esta contribución (en la biblioteca de la Universidad de Graz), las cartas de Schuchardt requirieron en buena medida del tendido de redes entre investigadores. El Archivo Lenz se encuentra preservado en la Universidad Metropolitana de las Ciencias de Educación en Santiago de Chile, y nosotros no teníamos ningún tipo de contacto en el país. Afortunadamente, durante nuestra participación en la $13^{\text {th }}$ International Conference on the History of the Language Sciences, conocimos a Darío Rojas, quien amablemente nos aportó imágenes de las cartas, y así las redes modernas obraron como reflejo de aquellas del pasado.

6 Cf. con respecto a esta sección en su totalidad, Sousa y Mücke (2016). 


\subsection{ACERCA DE LA CORRESPONDENCIA}

Las 9 piezas de correspondencia conservadas en Santiago de Chile y Graz fueron intercambiadas entre 1892 y 1926 . A partir de estas piezas disponibles, hemos podido deducir que faltan algunas más. Ya desde el comienzo, no hemos podido dar en las cartas con un pasaje mencionado en Lenz (19261927 y 1928):

Respecto del Papiamento me escribió Schuchardt: "Yo mismo he mencionado el papiamento sólo ocasionalmente. Creía siempre, que, siendo suficientemente conocido, merecería algún día un tratamiento serio de alguna otra persona. Nunca lo he perdido de vista". (Lenz 1926: 703, 1928: 11)

La primera carta de Lenz a Schuchardt es en respuesta a la reseña que este último hace de Wulff (1889 y 1891), donde mencionaba muy elogiosamente la obra de Lenz Zur Physiologie und Geschichte der palatalen (Lenz 1888). La respuesta de Lenz deja ver ya algo de lo que habrá de controvertido en sus futuros trabajos (Lenz 1891, 1892, 1893a y 1893b) acerca de la influencia de las lenguas nativas sudamericanas en el español chileno, y de su conexión con su trabajo más temprano:

Mit dem Chilenischen habe ich, glaube ich, Glück gehabt. Bisher habe ich noch keine Ahnung, ob sich eine ähnlich starke ethnologische Beeinflussung in Amerika noch einmal findet. Aber auch dieses eine Beispiel wird für die Sprachgeschichte von Wichtigkeit sein. Bei den Palatalen habe ich das 'Wie' der Entwickelung zeigen wollen, hier erkennen wir einmal klar das 'Warum'. (Lenz a Schuchardt, julio de $1892 ; \mathrm{N}^{\circ} 06397$ )

[Con el chileno creo que he tenido suerte. Hasta ahora no tengo idea acerca de si se encuentra en América algún otro caso de una influencia etnológica de similar vigor. Pero también este ejemplo singular será de importancia para la historia de la lengua. Con las palatales quise dar cuenta del "cómo" del desarrollo, aquí puede reconocerse claramente el "por qué"].

Se hace también bastante claro que Lenz se veía a sí mismo aislado del centro científico que representaba Europa, lo que lo llevaba a enfatizar la importancia del tendido de redes a través del intercambio epistolar:

Glauben Sie, verehrter Herr Professor, es tut einem hier doppelt wohl, zu erfahren, daß man noch nicht von allen Fachgenossen in Europa vergessen ist und ein solcher kleiner Ansporn ist hier nötig um nicht den 
Mut zum wissenschaftlichen Arbeiten zu verlieren, das bei dem Mangel von Bibliotheken und der Entfernung von den Druckorten nur eine halbe Freude ist. (Lenz a Schuchardt, julio de 1892; N 06397)

[Créame, admirado Profesor, es doblemente gratificante aquí saber que uno no ha sido olvidado aún por todos los colegas en Europa, y un pequeño estímulo como este es necesario aquí para no perder el ánimo en el trabajo científico, que ante la falta de bibliotecas y la distancia de los centros editores solo es una satisfacción a medias].

Su contacto, en lo aparente esporádico hasta 1921, se intensifica solo luego de que Lenz tomara conocimiento del papiamento. Aún en 1921, mucho tiempo después de su última publicación original sobre una lengua criolla (Schuchardt 1914a), Schuchardt era visto como la autoridad académica en esta materia (Lenz 1926-1927: 702). Por lo tanto, no debería sorprender que Lenz tomara la iniciativa de contactar a Schuchardt poco después de su llegada a Alemania. En su carta del 14 de junio de 1921, Lenz explica cómo entró en contacto con el papiamento. Durante las tres semanas de su viaje desde Curazao a Europa, Lenz había redactado 50 páginas manuscritas con muestras lingüísticas, y explicaba a Schuchardt la metodología que había aplicado para ello ${ }^{7}$. Natividad Sillie, el cocinero a bordo del buque, había suministrado a Lenz cuentos folclóricos, canciones, y sus propias creaciones literarias en verso y prosa. Más aún, Sillie también se ocupaba de leer en voz alta, permitiendo que Lenz tomara nota de la fonética y otros aspectos. Con la firme convicción de que sus notas merecían ser publicadas, Lenz buscó la ayuda de Schuchardt para obtener referencias bibliográficas. Aquí comienza el tendido de redes decimonónico.

E1 25 de junio de 1921, en respuesta a una correspondencia que no había sido sostenida, Lenz agradece a Schuchardt por las referencias, pregunta por una posible oferta de duplicados de este mismo autor, y establece su opinión acerca de Schuchardt (1914a). En el postscriptum, hace un breve examen de Gatschet (1885) y afirma su esperanza de obtener más material proveniente de Curazao. Pocos días después, Lenz expresará su gratitud por la oferta de duplicados, afirmando también que comenzará a trabajar en el papiamento en 1922, cuando estuviera de regreso en Chile. A partir de la extensa bibliografía que ofrece su descripción gramatical del papiamento (Lenz 1928: 18-29), puede identificarse la lista provista por Schuchardt, así como cuáles fueron los libros finalmente enviados a Lenz como duplicados.

7 De acuerdo con Labarías y Cárdenas (1998: 38), se contabilizan 80 páginas manuscritas en el Archivo Rodolfo Lenz. 
Lenz (1928: 21-23) también presenta una lista de publicaciones que había adquirido en Curazao. Estas listas son de especial interés, puesto que no nos ha sido posible localizar ninguno de los materiales acerca del papiamento reunidos por Schuchardt entre los papeles del autor preservados en Graz. Solo hallamos dos de los 25 trabajos mencionados; el resto no ha sido catalogado por Weiss (1986b), ni tampoco por Wolf (1993).

¿Por qué, no obstante, demoró tanto la elaboración y publicación de su obra pionera sobre el papiamento (Lenz 1928)? En la siguiente carta se pueden encontrar algunos indicios de los obstáculos interpuestos. La carta data de 1925 y fue escrita en respuesta al envío de Schuchardt (1925a). Además de la coincidencia de opinión en muchos temas relativos a la evolución lingüística y las afinidades entre lenguas, Lenz comenta que las revistas científicas europeas habían resultado inasequibles en Chile desde el comienzo de la Primera Guerra Mundial. Esto significa que Lenz dependía de su propia biblioteca y de las publicaciones que pudiera recibir mediante las redes de que disponía:

Leider fühlte ich auch wieder das Unglück meiner Vereinsamung, im letzten Winkel der Welt, wo ich ausser meiner eignen Bibli[o]thek kaum ein einziges wissenschaftliches Buch zu sehen bekomme. Seit dem Kriege habe ich keine wissenschaftlichen Zeitschriften aus Europa bekommen und im Instituto Pedagógico gieb[t] es solche überflüssigen Dinge wie Gröber's Zeitschrift und Romania schon seit 1909 nicht mehr. (Lenz a Schuchardt, abril de 1925; $\mathrm{N}^{\circ}$ 06401)

[Desgraciadamente volví a sentir también el infortunio de mi aislamiento "en el último rincón del mundo", donde más allá de mi propia biblioteca apenas llego a ver algún libro científico. Desde la guerra no he recibido mas publicaciones científicas de Europa y en el Instituto Pedagógico cosas superfluas como la revista de Gröber y Romania no las hay ya desde 1909].

De todas formas, la guerra no era el único acontecimiento sociohistórico que podía influir en el desarrollo de la ciencia. Lenz informa que, al llegar a Chile en 1921, fue designado director del Instituto Pedagógico y, algunos meses más tarde, durante una protesta estudiantil, su secretario había robado 10000 pesos. Esto lo había dejado prácticamente arruinado e incapaz de trabajar. Aún una vez que Lenz estuvo en condiciones de ocuparse del papiamento, a partir de 1923, encontró nuevos obstáculos a su investigación: su casa debió atravesar alguna suerte de reforma y sus clases sumaban hasta 18 horas semanales. No obstante, la parte gramatical de la monografía estaba casi terminada. Para marzo de 1926, Lenz comunicaba a Schuchardt que esperaba publicar sus estudios sobre el papiamento en ese mismo año, lo que 
sucedió luego de superar un nuevo obstáculo: de acuerdo con la carta del 17 de noviembre de 1926, los Anales de la Universidad de Chile solo podrían publicar trimestralmente, debido a la falta de financiamiento. Esto llevó a la publicación parcial del estudio, en siete artículos separados en 1926 y 1927 en los Anales $^{8}$. Por esta causa, Lenz solo pudo enviar a Schuchardt la primera parte de la descripción gramatical junto con esa carta. En ese momento, Lenz expresaba su alineamiento con la posición teórica de Schuchardt en cuanto a las lenguas criollas, no obstante el hecho de que este nunca había profesado en ninguno de sus artículos la noción de que las lenguas criollas fueran básicamente minimalistas y no manifestaran huellas de las lenguas de sustrato (Lenz 1928: 14):

Wie Sie sehen werden, bin ich ganz ihrer Ansicht über das Kreolische: es ist "gramática mínima" aber nicht "africana". (Lenz a Schuchardt, noviembre de 1926; No. 06403)

[Como podrá ver, comparto por completo su opinión sobre el criollo: es "gramática mínima" pero no "africana"].

Se han identificado dos posturas teóricas en el trabajo de Schuchardt sobre las lenguas criollas: una aproximación sustratista en los 1880 y una más universalista en los 1910 (Gilbert 1980: 8); pero ninguna de ellas coincide con la aserción de Lenz. Si volvemos a la carta enviada el 26 de abril de 1925, podemos observar que Lenz confiesa que su trabajo descansa en su mayor parte en los artículos publicados por Schuchardt acerca de los criollos. Más aún, podría pensarse en pasajes que podrían haber conducido a Lenz a suponer que él y Schuchardt estaban de acuerdo:

Es ist richtig, wir haben keine Divergenz, sondern Parallelismus; sie [las lenguas criollas atlánticas, JM/SMdS] sind aus verschiedenem Stoff nach dem gleichen Plan, in gleichem Stil gebildet. (Schuchardt 1914a: vii)

[Es cierto, no hay ninguna divergencia, sino paralelismo, ellas (las lenguas criollas atlánticas) fueron construidas a partir de materiales distintos, siguiendo el mismo plan, con el mismo estilo].

Podría argüirse que desde esta posición es posible establecer un vínculo directo con la perspectiva de Lenz sobre el papiamento como poseedor de la "gramática más sencilla" (Bachmann 2004: 386), un vínculo que fue hecho

\footnotetext{
Ni los artículos ni la monografía pudieron hallarse en la Biblioteca de la Universidad de Graz.
} 
posible a través del tendido - a veces obstruido- de redes. Nuestro interés por entender la fuente de esta coincidencia entre los puntos de vista de Lenz y Schuchardt acerca de la gramática mínima nos condujo a la siguiente, larga cita, que a su vez nos conecta con otro tema controvertido:

Sehr geeignet für die Erläuterung dieser Schwierigkeiten ist ein Fall den Meillet ([1914:] 411) selbst aufs Tapet bringt, der der kreolischen Mundarten, deren Entstehung und Entwickelung im hellsten Lichte vor uns liegt. Er wählt als Beispiel das Kreolische von Martinique und behauptet: "le peu que le créole a de grammaire est de la grammaire française"; von der Konjugation sei nur der Infinitiv übrig geblieben. Aber dieser ist als Verb schlechtweg übernommen worden, durchaus nicht in seiner französischen Bedeutung, und die Grammatik ist, wenngleich wesentlich mit französischen Mitteln gebildet, keine französische; vgl. z. B. moin $k a$ parler $(\boldsymbol{k} a$ ist portugiesisch $)=$ je parle, moin té $k a$ parler = je parlais. Sie ist aber auch keine afrikanische; sie ist eine naturwüchsige, sie beruht auf Urschöpfung. Ihrer innern Form nach, die allerdings von Meillet ganz beiseite gesetzt wird, bleibt sie die gleiche durch alle negerkreolischen Mundarten hindurch, und so dürften wir denn von einem Negerkreolisch reden das nach den Gegenden mit französischen, englischen usw. Lehnwörtern ausgefülltt wäre. (Schuchardt 1914b: 4-5; cursivas en el original, negritas de los autores de este capítulo).

[Para la explicación de estas dificultades resulta muy adecuado un caso que el propio Meillet (1914: 411) trae a cuento: el de los idiomas criollos, cuyo surgimiento y desarrollo se encuentra ante nosotros expuesto a toda luz. Meillet toma como ejemplo el criollo de Martinica y afirma: "lo poco que el criollo tiene de gramática viene de la gramática francesa", de la conjugación sólo quedaría el infinitivo. Pero ha sido adaptado directamente como verbo, de ninguna manera en su significado francés, y la gramática, aunque esté formada esencialmente con medios franceses, no es en modo alguno francesa; por ejemplo moin ka parler ( $\boldsymbol{k} \boldsymbol{a}$ es portugués) $=$ je parle, moin té ka parler $=$ je parlais. Pero tampoco es ninguna gramática africana; ha crecido naturalmente, procede de una creación originaria. Por su forma interna, que es de todas formas completamente dejada de lado por Meillet, se mantiene idéntica a través de todos los idiomas negro-criollos, y por tanto podemos hablar de un negro-criollo que de acuerdo a la zona sería completado con préstamos léxicos franceses, ingleses, etc.].

Si bien Schuchardt, en la nota a pie de página a partir de esta última frase, observa que esta cuestión deberá ser discutida en la introducción a su estudio del saramacca (Schuchardt 1914a), el uso de las lenguas criollas en 
la discusión acerca del parentesco entre lenguas toca una vez más el tema más controversial de la lingüística contemporánea: ¿Son las lenguas criollas un grupo tipológicamente separado de otras lenguas naturales? ¿Y qué implicancias tiene la respuesta que se dé a esta pregunta? Otra observación interesante que debe hacerse concierne a la influencia de las aserciones de Lenz sobre otros lingüistas, lo que nos lleva (otra vez) al problema del excepcionalismo criollo. A pesar de que no hay referencia directa, Hjelmslev (1939) se apoya en Lenz (1928) para contradecir la noción de que "la gramática criolla es la gramática reducida al mínimo" (Hjelmslev 1939: 373):

L'expression des formes grammaticales est dans les langues créoles à l'optimum: univocité paradigmatique (manque de 'déclinations' et de 'conjugaisons' différentes); univocité syntagmatique (chaque morpheme a son expression à lui); ordre de mots pourvu d'une valeur grammaticale. Ceci pourrait faire penser que le système grammatical des langues creoles (l'inventaire et la configuration des morphemes fondamentaux) est le système grammatical à l'optimum. Discussion théorique de cette hypothèse et verification sur quelques langues creoles proprement dites (creolized languages, surtout le Papiamento). (Hjelmslev 1939: 373; cursivas en el original).

[La expresión de las formas gramaticales alcanza su forma óptima en las lenguas criollas: univocidad paradigmática (carencia de 'declinaciones' y de 'conjugaciones' diferentes); univocidad sintagmática (cada morfema lleva su expresión en sí); orden de palabras provisto de valor gramatical. Esto podría hacer pensar que el sistema gramatical de las lenguas criollas es el sistema gramatical en nivel óptimo. Discusión teórica de esta hipótesis y verificación en algunas lenguas criollas propiamente dichas (lenguas criollizadas, sobre todo el papiamento)].

\section{LA CORRESPONDENCIA}

3.1. Rasgos generales de la correspondencia y convenciones editoriales

Como se ha dicho antes, la correspondencia preservada en Santiago de Chile y Graz consta de un total de nueve piezas que datan del período entre 1892 y 1926. Las cartas conservadas en Graz llevan las signaturas de 06397 hasta 06403, mientras las conservadas en Santiago llevan las signaturas 3-0347 y 3-0348. La disposición cronológica de la correspondencia existente es como sigue: 


\section{2 - 1 carta de Lenz a Schuchardt \\ 1897 - 1 postal de Schuchardt a Lenz \\ 1910 - 1 carta de Schuchardt a Lenz \\ 1921 - 3 cartas de Lenz a Schuchardt \\ 1925 - 1 carta de Lenz a Schuchardt \\ 1926 - 2 cartas de Lenz a Schuchardt}

La transcripción de las cartas presentadas aquí puede exhibir algunas pequeñas modificaciones con respecto a las originales, cuyo único propósito ha sido el de posibilitar una mejor lectura. Las palabras subrayadas en las cartas han sido transcriptas en cursivas, mientras que el subrayado ondeado ha sido reproducido como negritas. Las palabras cursivas han sido transcritas como negritas. La marca de cambio de página solo se aportará después de la segunda página. Esto significa que al comienzo de la segunda página se encontrará el signo [2] y al comienzo de la tercera el [3], y así sucesivamente. Se han utilizado corchetes para las palabras indescifrables. Dado que se ha mantenido la escritura original, se ha hecho uso de [sic] en caso de necesidad.

\subsection{LAS CARTAS}

\subsubsection{Carta 01-06397}

Corresp. No. 01

Bibl. No. 06397

Tipo: carta manuscrita de Lenz a Schuchardt

Lugar: Santiago de Chile

Fecha: 31 de julio de 1892

Santiago de Chile, 31. Juli 1892

casilla 844

Hochverehrter Herr Professor!

Durch die Übersendung Ihrer Rezension von Wulffs Arbeiten über das Andalusische und die Rolle des Akzentes in der Versbildung haben Sie mir in mehr als einer Hinsicht ein [sic] große Freude bereitet und mich zu gleicher Zeit an eine Dankespflicht älteren Datums erinnert. Ich habe nämlich vor etwa zwei Monaten von meinem Freunde $\mathrm{D}^{\mathrm{r}}$ Moritz Goldschmidt in Wolfenbüttel Ihren Brief vom März vorigen Jahres erhalten. Derselbe hat den Ozean dreimal gekreuzt, ehe er in meine Hände gelangt ist. Das 
erste mal, als er vor einem Jahre ankam, ist er, ich weiß nicht durch welche Dummheit der Postbehörde, als unbestellbar wieder in die Heimat zurückgewandert. So konnte ich erst jetzt von Ihren schätzenswerten Winken betreff der Indianersprachen Kenntnis nehmen. Inzwischen hatte ich mich selbst nach der indianischen Litteratur etwas mehr umgetan und bin jetzt wenigstens im großen und Ganzen orientiert. Middendorfs Keshua- und Aimarágrammatiken [nota al margen de Lenz: die übrigens als wissenschaftliche Werke höchst mangelhaft sind, so schön auch das Material ist. Er deutet ja nicht einmal an, daß es eigentlich ein Unsinn ist in einer agglutinierenden Indianersprache unsere grammatische Einteilung in Substantivum, Verbum, Pronomen etc zu finden. Nirgends ein Versuch die Wortbestandteile zu erklären! Vielleicht wage ich nächstens eine Rezension.] sind in meinem Besitz, die Chimusprache hoffentlich bereits unterwegs. Hier auf der Nazionalbibliothek sind eine ganze Anzahl älterer und neuerer Werke; es giebt aber noch keinen Katalog und alles Material würde für mich gar nicht existieren, wenn mir nicht der Direktor den Zutritt zu den Büchersälen persönlich gestattet hätte. Da kann ich mir nun suchen, was ich brauche - und manchmal recht lange suchen, denn die Ordnung ist vorläufig nur geographisch gemacht und oft genug nicht inne gehalten. - Im übrigen ist es hier fast unmöglich in Amerika erschienene Werke zu erhalten, wenn man nicht am Erscheinungsort einen guten Freund hat; denn der Buchhandel ist hier noch recht embryonal. Man ist wesentlich auf den glücklichen Zufall angewiesen. Ich würde Ihnen daher sehr verpflichtet sein, wenn Sie mir vielleicht gelegentlich bei solchen Angelegenheiten behilflich sein wollten, - etwa mit der Tupibibliographie von do Valle Cabral, die Sie in dem Briefe an meinen Freund erwähnten. Ich bin gern zu Gegendiensten bereit, $|2|$ und würde Ihnen z. B. Rodriguez' Diccionario de Chilenismos als Gegengabe anbieten können, wenn Sie das Buch noch nicht besitzen. - Mich interessieren in erster Linie allerdings nur die Indianersprachen auf heutigen romanischen Gebieten. Über das Araukanische bin ich schon ganz gut unterrichtet und habe es auch schon Ort und Stelle zu studieren begonnen. Hoffentlich werde ich in diesem Sommer einmal einen längeren Studienaufenthalt an der Frontera ermöglichen. - Die höchst interessante chilenische Lautlehre habe ich bereits in einer Reihe von Artikeln behandelt, die mit Ausnahme des letzten (vom März diesen Jahres) schon vor April des vorigen an Vietor für die Phonetischen Studien abgegangen und auch angekommen sind. Der Druck hat sich leider so verzögert, daß ich erst mit letzter Post die Nachricht von dem Korrekturlesen des ersten Abschnittes durch meinen Freund Goldschmidt erhielt. Die kleine Miszelle, die im vorigen Juni oder Juli bei Gröber in der Zft. f. rom. Phil. erschien, sollte eigentlich nur auf die Veröffentlichung in den Phon. Stud. hinweisen, die 
mir dadurch nahegelegt war, daß ich seit dem ersten Bande als Mitarbeiter der Phon. Stud. fungierte, ohne etwas geschrieben zu haben. Heute habe ich einen zweiten größeren Aufsatz an Gröber abgesandt, der hoffentlich nur den Anfang einer längeren Reihe von Publikazionen bilden wird. Ich glaube er wird von Interesse sein. Ich habe, wie ich meine, sicher nachgewiesen, daß fast die gesammte Entwicklung der chilenischen Lautlehre auf den Einflusse des Araukanischen beruht, ein sprachhistorisches Faktum wie es in der Klarheit noch nie hat konstatiert werden können. So ist es mir denn hoffentlich abermals mehr oder weniger gelungen eine "Projekzion vom Höheren" wie Sie es richtig nennen, zu unternehmen. - Was Sie an der betreffenden Stelle Ihrer trefflichen Rezension sagen hat mich aufrichtig gefreut. Ist es doch das erste Mal, daß meine Arbeit über die Palatalen von diesem Standpunkt aus richtig aufgefaßt wird. Wenn Sie es tadeln daß ich meine Beispiele nur aus den romanischen Sprachen gewählt habe, so sind Sie von Ihrem Standpunkt und bei der Weite Ihres sprachlichen Gesichtskreises durchaus im Recht. Es war ja auch keineswegs prinzipiell von mir so gemeint. Ich wollte nur ein sicheres Material haben, und glaubte daher mich auf das mir gewohnte Gebiet beschränken zu müssen, um nicht infolge $|3|$ mangelhafter Sachkenntnis in falsche Beurteilungen zu verfallen. Deshalb ließ ich eine Anzahl Materialien die ich aus dem Sanskrit und besonders dem Litthauischen und Lettischen das ja so reich an Palatalentwickelungen ist, gesammelt hatte, schließlich fort, denn diese Sprachen waren mir nur aus oberflächlichem Studium aber nicht in ihrer ganzen Entwicklung bekannt. Es wäre ein Prunken mit geliehener und nur teilweise verdauter Gelehrsamkeit geworden, bei der der Kenner vielleicht doch irgendwo das Eselohr unter der Löwenhaut entdeckt hätte. Ich denke Sie werden diese Gründe als stichhaltig erkennen und dem Anfänger verzeihen der ehrlich genug ist sich den weiten Blick des Meisters nicht anzumaßen, so lange er ihn trotz Brillen und Fernrohre nicht hat.

Mit dem Chilenischen habe ich, glaube ich, Glück gehabt. Bisher habe ich noch keine Ahnung, ob sich eine ähnlich starke ethnologische Beeinflussung in Amerika noch einmal findet. Aber auch dieses eine Beispiel wird für die Sprachgeschichte von Wichtigkeit sein. Bei den Palatalen habe ich das "Wie" der Entwickelung zeigen wollen, hier erkennen wir einmal klar das "Warum". Wir werden nicht oft so glücklich sein, den inneren Grund eines Lautwandels so klar zu erkennen. Ich bin übrigens sehr neugierig, ob das von mir gebrachte Material auch andere ebensofest von meiner Behauptung überzeugen wird, wie ich davon überzeugt bin. - Ich wurde zuerst darauf gebracht, durch eine Zufällige Äußerung unseres alten deutsch-chilenischen Nestors der Naturwissenschaften, des Herrn $D^{r}$. Philippi, der einmal behauptete daß Wort zapallo könne nicht araukanischen Ursprungs sein, weil 
die Araukaner kein S u. Z hätten. Da wurde mir auf einmal klar, warum dem Chilenen das S so unangenehm ist; ich suchte nun in der arauk. Grammatik und fand dort das apiko-praepalatale $\mathrm{t}^{\mathrm{v}}$, das der Chilene statt tr gebraucht als zweiten Angelpunkt. Alles übrige gruppiert sich um diese beiden Facta; und wenn nun auch etwa das frikative $\mathrm{q}$ statt $\mathrm{g}$ nicht auf indianischem Einflusse beruht, so ist damit dem Ganzen kein Abbruch getan, denn daß jeder Lautwandel überall selbständig vorkommen kann, ist, wie Sie richtig bemerken, kein Zweifel; nur das Zusammentreffen mehrerer Punkte kann die Wahrscheinlichkeit der ethnologischen Gründe vermehren.

Ihre Klage, daß das spanische Lautsystem noch keine genügende Bearbeitung gefunden, wird hoffentlich durch meine Chil. Stud. etwas weniger von ihrer Richtigkeit eingebüßt haben. Araujo ist, wie Sie mit Recht sagen, nur mit Vorsicht zu genießen. Mir scheint er hat die Lautphysiologie |4| zwar eifrig studiert, aber noch nicht recht verdaut. Übrigens ist er eben ein Spanier und denen steckt im Sprachwissenschaftlichen der Kopf noch tief im Mittelalter. Kennen Sie seine gramática "razonada" histórica(!)-crítica(!) des französischen? Sie prangt mit dem Wuste eines mittelalterlichen Polyhistors - echt spanisch. Aber Sie tuen ihm doch ein mal Unrecht. Wenn er das $d$ von dragon neben $t$ in atlas stellt, so ist dabei nur töricht sein Zeichen $t$ er meint damit nicht die Kehlkopfartikulazion sondern die Zungenartikulazion. Sein $d(l)$ ist stimmhaft aber vollständiger Okklusivlaut, während sonst $d$ im Spanischen unvollständig geschlossen, etwas frikativ ist. Aber der Stimmton bei atlas ist richtig; auch der gebildete Chilene und Peruaner sagt ad(a)las ebenso wie tégnico statt técnico; ich habe beides in den Chil. Stud. erwähnt. Auch die Ausprache salu९ kommt wirklich vor. Ich glaube allerdings vorläufig, daß sie ein Kunstprodukt der Schulaussprache ist. Daß sie irgendwo volkstümlich sei ist mir noch nicht bekannt.-

Die Arbeit von Wulff über das Andalusische ist mir leider nicht bekannt. Ich schreibe gleichzeitig an ihn um womöglich um einen Separatabdruck zu bitten. War es Zufall, daß ich gleichzeitig mit Ihrer Rezension von Herrn Prof. Wulff seine Abhandlg. über Akzent in der Versbildung und die Metodiska Ljudöfningar zugeschickt erhielt? Jedenfalls war jener Tag für mich ein Freudentag. Glauben Sie, verehrter Herr Professor, es tut einem hier doppelt wohl, zu erfahren, daß man noch nicht von allen Fachgenossen in Europa vergessen ist und ein solcher kleiner Ansporn ist hier nötig um nicht den Mut zum wissenschaftlichen Arbeiten zu verlieren, das bei dem Mangel von Bibliotheken und der Entfernung von den Druckorten nur eine halbe Freunde ist. Hier kann man auf Verständnis natürlich garnicht rechnen. Unsere ganze Facultad de Humanidades zählt unter den Chilenen nur einen einzigen Gelehrten, der diesen Namen verdiente, Don Diego Barros Arana, den Verfasser der großen Geschichte von Chile. Philologie ist im Südamerika 
ein unbekanntes Ding. Nur Cuervo ist, wie der alte Pott in einem in der Einleit[un]g des Lenguaje bogotano veröffentlichten Briefe sagte "ein weißer Rabe". Ich fürchte man wird mich steinigen, wenn ich hier in den Analen der Universität publiziere, die Aussprache des Chilenischen stehe unter indianischem Einfluß! - Nun, nochmals besten Dank von Ihrem ergebensten

\section{Rudolf Lenz}

\section{Santiago de Chile}

casilla 844.

\section{Traducción}

Santiago de Chile, 31 de julio de 1892

casilla 844

\section{Veneradísimo Profesor!}

Con el envío de su reseña de los trabajos de Wulff sobre el andaluz y el rol del acento en la construcción del verso ${ }^{9}$ me ha deparado Usted en más de un aspecto una gran alegría, recordándome al mismo tiempo un deber de gratitud de más antigua data. Y es que hace unos dos meses recibí de parte de mi amigo el $\mathrm{D}^{\mathrm{r}}$ Moritz Goldschmidt de Wolfenbütte $\mathrm{l}^{10}$ su carta de marzo del año pasado ${ }^{11}$. Esta ha cruzado el Océano tres veces antes de llegar a caer en mis manos. La primera vez que llegó, hace un año, no sé gracias a qué tontería de la oficina postal, retornó a la patria como imposible de entregar. Por lo tanto, recién ahora he podido tomar conocimiento de su invalorable guiño con respecto a las lenguas indígenas. Entretanto me había ocupado

9 Schuchardt (1892; HSA 261) reseñó dos obras de Frederik Amadeus Wulff (18451930): Un chapitre de phonétique avec transcription d'un texte andalou (Wulff 1889) y "Von der Rolle des Akzentes in der Versbildung" (Wulff 1891). En este artículo, que es bastante más que una reseña de Wulff $(1889,1891)$, Schuchardt se refiere también a Lenz (1888): "R. Lenz hat in seiner Arbeit über die Palatalen den richtigen Weg eingeschlagen, nur hätte er, der doch hier Schleicher zum Vorgänger hatte, sich bei der Wahl seiner Beispiele nicht auf das Romanische beschränken sollen" [En su trabajo sobre las palatales, R. Lenz ha encarado el camino correcto, sólo que este autor -que tenía aquí como predecesor a Schleicher- no debería haberse limitado en la elección de sus ejemplos a las lenguas románicas] (Schuchardt 1892: 244).

10 Posiblemente Moritz Goldschmidt (1864-?). Puede encontrarse una conexión entre Goldschmidt y Lenz en la Festgabe für Wendelin Foerster, donde contribuyeron ambos autores (Goldschmidt 1902, Lenz 1902). Por lo demás, Goldschmidt hizo sus estudios en la Universidad de Bonn en la misma época en la que los hizo Lenz (cf. Goldschmidt 1887: 68).

11 Esta carta aún no ha sido hallada. 
un poco más de la literatura sobre el tema y estoy ahora a grandes rasgos al menos orientado. Las gramáticas quechua y aimara de Middendorf [nota al margen de Lenz: las cuales son bastante deficientes en tanto obras científicas, aunque el material sea muy bello. No indica siquiera una vez el sinsentido de encontrar nuestra división gramatical en sustantivo, verbo, pronombre en una lengua indígena aglutinante. ¡En ningún lado intenta explicar los componentes de la palabra! Quizás me atreva próximamente a hacer una reseña.] están en mi poder, la lengua Chimú esperemos que ya en camino ${ }^{12}$. Aquí en la Biblioteca Nacional hay toda una cantidad de obras nuevas y antiguas; no hay sin embargo aún un catálogo, y todo ese material no existiría en absoluto para mí si el director no me hubiera permitido el ingreso personalmente a las salas de libros. Ahora puedo buscar allí lo que necesito $-\mathrm{y}$ a veces durante un largo rato, ya que el orden está dispuesto hasta ahora provisoriamente según la geografía, y con bastante frecuencia tampoco es respetado-. Por lo demás, aquí resulta casi imposible obtener obras publicadas en América, si no se tiene un buen amigo en el lugar de edición, ya que el comercio del libro es aquí aún bastante embrionario. Uno se encuentra en lo esencial librado a algún azar afortunado. Por lo tanto, estaría muy agradecido, si Usted quizás quisiera ocasionalmente brindarme su ayuda en tales asuntos - por ejemplo, con la bibliografía tupí de do Valle Cabral, que Usted mencionaba en la carta a mi amigo ${ }^{13}$. Estoy gustosamente dispuesto a corresponder esos favores, $|2|$ y podría ofrecerle por ejemplo el Diccionario de Chilenismos de Rodríguez ${ }^{14}$ en retribución, en caso de que aún no posea este libro. -A mí, no obstante, me interesan antes que nada solo las lenguas indígenas en territorios actualmente románicos. Sobre el araucano ya estoy muy bien instruido y he comenzado también a estudiarlo en el mismo lugar en que se habla. Espero poder hacer una estancia de estudio extensa en la Frontera este verano. He tratado ya la interesantísima fonética chilena en una serie de artículos que, con excepción del último (de

12 Ernst Wilhelm Middendorf(1830-1908) publicó entre 1890 y 1892 los seis volúmenes de Die einheimischen Sprachen Perus. El primer volumen se titula Das Runa Simi oder die Keshua-Sprache, wie sie gegenwärtig in der Provinz Cuzco gesprochen wird (Middendorf 1890), el quinto volumen apareció como Die Aimara-Sprache (Middendorf 1891), y el sexto como Das Muchik oder die Chimu-Sprache (Middendorf 1892).

13 Alfredo do Valle Cabral (1851-1894) compiló la "Bibliographia das obras tanto impressas como manuscriptas, relativas á lingua tupi ou guarani tambem chamada lingua geral do Brazil" (Cabral 1880-1881).

14 Zorobabel Rodríguez (1839-1901), autor del Diccionario de chilenismos (Rodríguez 1875). De acuerdo con Weiss (1986a: 64), en la biblioteca de Schuchardt había una copia de esta obra. 
marzo de este año) y antes de abril del pasado envié y también llegaron a Vietor para los Phonetischen Studien. Desgraciadamente, la impresión se ha demorado tanto que recién con el último correo recibí el mensaje con la corrección de la primera sección por parte de mi amigo Goldschmidt ${ }^{15}$. La pequeña miscelánea que apareció el pasado junio o julio en el Zft. f. rom. Phil. de Gröber, debía de hecho referir solo a la publicación en los Phon. Stud., la que me hacía así entender, que apareciera desde el primer volumen de los Phon. Stud. como colaborador, sin haber escrito nada ${ }^{16}$. Hoy he enviado un segundo artículo de mayor porte a Gröber, que espero constituya solo el comienzo de una serie más larga de publicaciones ${ }^{17}$. Creo que será de interés. Como sostengo, he demostrado con seguridad que casi el completo desarrollo de la fonética chilena se funda en la influencia del araucano, un hecho de historia lingüística como no ha podido constatarse nunca hasta ahora con tal claridad. Así, me ha sido dado, espero, emprender una "proyección desde lo superior", como Usted correctamente lo denomina ${ }^{18}$. -Lo que Usted dice en el pasaje en cuestión de su acertada reseña me ha dado una verdadera alegría. Y es que es la primera vez que mi trabajo sobre las palatales es considerado como se debe desde ese punto de vista. Cuando Usted critica que haya escogido mis ejemplos sólo de entre las lenguas románicas, tiene toda la razón, desde su punto de vista y habida cuenta de la amplitud de su horizonte lingüístico. De ningún modo pretendía yo darlo a

15 El primer artículo apareció como "Chilenische Studien. I." (Lenz 1892) en el periódico Phonetische Studien, editado por Wilhelm Viëtor. En la primera página Lenz refiere la literatura relevante en torno a los criollos y dialectos mixtos similares ("kreolischen und ähnlichen mischdialekten") de Schuchardt y Coelho, a los que no tenía acceso (Lenz 1892: 272). El artículo tiene fecha del 9 de enero de 1891. Los "Chilenische[n] Studien. II. III." aparecieron más tarde como Lenz (1893b), pero fechados el 9 de marzo de 1891.

${ }_{16}$ El artículo "Zur spanisch-amerikanischen Formenlehre" (Lenz 1891) se publicó en el Zeitschrift für romanische Philologie.

17 Este artículo apareció como "Beiträge zur Kenntnis des Amerikanospanischen" en el Zeitschrift für romanische Philologie (Lenz 1893a), y está fechado en el índice de la revista con fecha del 31 de julio de 1892. En una nota a pie de página en la p. 190, Lenz hace mención de que Schuchardt le había enviado en esos días su reseña de Wulff.

18 Schuchardt escribe en su reseña de Wulff, a lo que sigue una referencia positiva a Lenz: "Jene verwirrende Buntheit welche die romanische Lautgeschichte selbst in der Darstellung des weite Umschau haltenden und tiefen Einblick anstrebenden Meyer-Lübke zu einer der unerquicklichsten Partien aller Wissenschaft macht, kann nur vereinfacht und geklärt werden wenn wir in ihr die Spezialisierungen von Allgemeinerem, die Projektionen von Höherem suchen" [Ese confuso colorido que hace de la historia fonética de las lenguas romance -tal como la presenta incluso Meyer Lübke, con su amplio panorama y su penetrante perspectivauna de las zonas más fastidiosas de toda la ciencia, sólo puede ser simplificada y aclarada si procuramos buscar las especializaciones desde lo más general, las proyecciones desde lo más alto] (Schuchardt 1892: 244). 
entender principalmente de esa forma. Solo quería tener un material seguro, y creí por ello deber restringirme al ámbito que habito, para evitar caer, a consecuencia $|3|$ de un conocimiento deficiente de las cosas, en juicios falsos. Por esa razón postergué finalmente una cantidad de materiales que había reunido del sánscrito, y especialmente del lituano y el letón, que es tan rico en desarrollos palatales, ya que esas lenguas me eran conocidas a partir de un estudio superficial, pero no en todo su desarrollo. Se habría convertido en un alarde a base de erudición prestada y sólo parcialmente digerida, en el cual el conocedor quizás hubiese descubierto en algún lado la oreja de burro bajo la piel de león. Pienso que Usted encontrará convincentes estos motivos y sabrá disculpar al principiante que es suficientemente honesto como para no arrogarse la mirada más abarcadora del maestro mientras no la tenga, a pesar de todos los lentes y telescopios.

Con el chileno creo que he tenido suerte. Hasta ahora no tengo idea acerca de si se encuentra en América algún otro caso de una influencia etnológica de vigor similar. Pero también este ejemplo singular será de importancia para la historia de la lengua. Con las palatales quise dar cuenta del "cómo" del desarrollo, aquí puede reconocerse claramente el "por qué". No creo que vayamos a tener con frecuencia la fortuna de poder distinguir tan claramente el motivo de un cambio fonético. Por lo demás, tengo mucha curiosidad de saber si el material por mí reunido también convencerá a otros de mi aseveración tanto como a mí. - Fui conducido allí primeramente por una expresión accidental de nuestro viejo Néstor germano-chileno de las ciencias naturales, el Dr. Philippi ${ }^{19}$, que una vez aseveró que la palabra zapallo no podría ser de origen araucano, porque los araucanos no tenían $\mathrm{S}$ y Z. Ahí se me hizo claro súbitamente, por qué al chileno le resulta tan incómoda la $\mathrm{S}$; busqué entonces en la gramática araucana y encontré allí el sonido ápico-prepalatal $\mathrm{t}^{\mathrm{v}}$, que el chileno utiliza en lugar de tr como segundo punto de apoyo. Todo lo demás se agrupa alrededor de estos dos hechos; y si ahora también por caso la fricativa q en lugar de g no se explica por la influencia indígena, eso no hace mella alguna en el todo, ya que, como Usted acertadamente señala, no hay duda de que cada cambio fonético puede presentarse en cualquier parte de manera independiente;

19 Rudolf Amandus Philippi (1808-1904), botánico y zoólogo alemán, emigró en 1851 a Chile, donde postuló a un cargo de Profesor de la Universidad en Santiago en 1853. Siguió a su hermano Bernhard Eunom Philippi (1811-1852), que desempeñó un papel importante en la organización de la migración alemana a Chile en el siglo XIX (Zirnstein 2001 y Lindgren 2001). 
solo la convergencia de varios puntos puede aumentar la verosimilitud de los fundamentos etnológicos.

Espero que su queja acerca de que el sistema fonético del español aún no ha sido suficientemente trabajado vea restado al menos un poco su acierto a través de mis Chil. Stud. De Araujo ${ }^{20}$, como Usted dice con razón, se puede sacar provecho solo con prudencia. A mí me parece que ha hecho un celoso estudio de la fisiología de los sonidos |4| pero no la ha digerido correctamente aún. Por lo demás, es un español, y ellos, en lo tocante a la lingüística, tienen su cabeza aún profundamente estancada en la Edad Media. ¿Conoce Usted una gramática "razonada" histórica(!)-crítica(!) del francés? Hace alarde de la mescolanza propia de un polígrafo medieval, algo auténticamente español. Pero en un punto Usted es injusto con él. Cuando pone la $d$ de dragon junto a $t$ en atlas, solo se trata de la necedad de su signo 7 ; con ello no refiere la articulación laríngea, sino la articulación de la lengua. Su $d(t)$ es sonora pero completamente oclusiva, mientras la $d$ en español tiene normalmente un cierre incompleto, es algo fricativa. Pero la sonoridad en ațlas es correcta; también el chileno y peruano culto dice ad(o)las así como tégnico en lugar de técnico; he mencionado ambas cosas en los Chil. Stud. También se presenta realmente la pronunciación salu $\vartheta$. Creo de todas formas provisoriamente, que se trata de un producto artificial de la pronunciación escolar. Que se encuentre en alguna parte popularmente me es desconocido aún.-

Lamentablemente, no conozco aún el trabajo de Wulff sobre el andaluz. Simultáneamente le estoy escribiendo a él ${ }^{21}$, para pedirle si es posible obtener una separata. ¿Fue casualidad que recibiera simultáneamente con su reseña del Prof. Wulff su estudio sobre el acento en la versificación y los Metodiska Ljudöfningar ${ }^{22}$ ? Sea como fuere, ese día fue para mí uno de felicidad. Créame, admirado Profesor, es doblemente gratificante aquí saber que uno no ha sido olvidado aún por todos los colegas en Europa, y un pequeño estímulo como este es necesario aquí para no perder el ánimo en el trabajo científico, que ante la falta de bibliotecas y la distancia de los centros editores solo es una satisfacción a medias. Aquí no puede contarse naturalmente con ninguna forma de comprensión. Toda nuestra Facultad de Humanidades no cuenta entre los chilenos más que con un solo erudito

20 En su reseña de Wulff, Schuchardt critica el artículo de Araujo, "Recherches sur la phonétique espagnole", en los Phonetische Studien (Araujo 1890, 1892).

21 Los autores de esta contribución no han podido encontrar aún ninguna carta de Lenz a Wulff.

22 Esto es, Metodiska ljudöfningar (Lyttkens y Wulff 1892). La correspondencia entre Wulff y Schuchardt no pudo ser hallada por los autores de este artículo. 
merecedor de ese nombre, Don Diego Barros Arana, el autor de la gran Historia de Chile ${ }^{23}$. La filología es en Sudamérica una cosa desconocida. Solo Cuervo es, como el viejo Pott lo dijo en una carta publicada en la introducción al Lenguaje bogotano, "un cuervo blanco"24. Temo que me vayan a lapidar si llego a publicar aquí en los Anales de la Universidad que la pronunciación del chileno está bajo influencia indígena! - Ahora sí, una vez más el mayor agradecimiento y los más atentos saludos,

D. Rudolf Lenz

Santiago de Chile

casilla 844 .

\subsubsection{Postal 02-3-0347}

Corresp. No. 029

Bibl. No. 3-0347

Tipo: postal manuscrita de Schuchardt a Lenz

Lugar: Graz, Austria

Fecha: 26 de noviembre de 1897

$\mathrm{S}$ [ehr] g[eehrter] K[ollege] [Ic]h sage Ihnen m[ei]nen besten Dank für Ihre Zusendungen. Die araukanischen Märchen werden mich wohl noch einmal näher beschäftigen - nämlich wenn ich dazu kommen sollte, mich über (gedruckte und ungedruckte) Kreolische Märchen zu äussern. Bitte auch Ihren Kollege Herr. F. Hanssen meinen Dank zu vermelden.

Mit bestem Gruss

Ihr erg[ebener]

H. Schuchardt

23 Diego Barros Arana (1830-1907), cf. Lenz (1893a: 212). Barros Arana escribió una Historia General de Chile en 16 volúmenes (Barros Arana 1884-1902).

24 El filólogo colombiano Rufino José Cuervo (1844-1911) estaba en contacto con ambos, Schuchardt y Lenz. Ambas correspondencias fueron publicadas por el Instituto Caro y Cuervo en Bogotá en la serie Archivo epistolar Colombiano. La correspondencia con Schuchardt fue editada por Bross (1968) y Schütz (1976). Cf. también las adiciones de Weiss (1981, 1984, 1986b). Schütz (1976) publicó también la correspondencia entre Lenz y Cuervo, y además de la intercambiada entre Cuervo y August Friedrich Pott (1802-1887). 


\section{Traducción}

M[uy] e[stimado] c[olega] le doy las gracias por Sus envíos. Los cuentos araucanos $^{25}$ van a darme trabajo más pronto, en cuanto haya llegado a dar mi opinión sobre los cuentos criollos (impresos y no impresos). Por favor exprésele mi agradecimiento también a su colega Sr. F. Hanssen ${ }^{26}$.

Con los mejores saludos

Atentamente,

H. Schuchardt

\subsubsection{Carta 03-3-0348}

Corresp. No. 03

Bibl. No. 3-0348

Tipo: carta manuscrita de Schuchardt a Lenz

Lugar: Graz, Austria

Fecha: 27 de septiembre de 1910

Graz; III,

Villa Malwine

27 Sept. ' 10

Sehr geehrte Herr Kollege

Empfangen Sie meinen allerverbindlichsten Dank für die Übersendung der zweiten Hälfte Ihres Dicc. etim. und zugleich meinen aufrichtigen Glückwunsch zur Vollendung des sch[ö]nen Werkes. Auf Anerkennung Ihrer Leistung dürfen Sie freilich wohl mehr bei uns, als in Ihrer Adoptivheimat rechnen, was ja $|2|$ auch aus Ihren Beilagen hervorgeht. Aber das sind doch nur zeitliche Hemmungen und Sie werden sich dadurch nicht von der Fortsetzung Ihrer indiano=spanischen Studien abschrecken lassen. Vielen Nutzen wird aus dem Wörterbuch die allgemeine Sprachwissenschaft ziehen.

25 Probablemente Lenz (1896), Araukanische Märchen und Erzählungen mitgeteilt von Segundo Jara (Kalvún). De acuerdo con Weiss (1986a: 173), Schuchardt poseía una copia de esta publicación.

${ }_{26}$ Friedrich Ludwig Christian Hanssen (1857-1919) era un romanista, que obtuvo su doctorado en Leipzig en 1882, donde ejerció luego también la docencia. En 1889 emigró a Chile. Hay una carta de Hanssen a Schuchardt entre los papeles de Schuchardt en Graz, con fecha del 7 de julio de 1898. De acuerdo con Weiss (1986a: 59), Schuchardt tenía una copia de la Spanische Grammatik auf historischer Grundlage de Hanssen (1910). 
Die Geschichte solcher Wörter wie tanda ist im höchsten Grade lehrreich. Das bask. chanda (ťsanda) - nach Azkue guip., zweifelhaft bizk. - = turno, vez, wird eine Deminutivform, für $* \tilde{t a n d a}(\tilde{\mathrm{t}}=\mathrm{tj})$, sein, von dem aus dem Span. übernommen tanda 1) roncal. Sant. = muchedumbre, rebaño 2) rom. $|3|=$ plazo, tandaka = á plazos (z. B. pagar á plazos, payer à termes).

Mit hochachtungsvollstem G[r]uß

Ihr ergebener

H Schuchardt

\section{Traducción}

Graz; III, Villa Malwine

27 Sept. ' 10

\section{Muy estimado colega}

Reciba Usted mi más encarecido agradecimiento por el envío de la segunda mitad de su Dicc. etim. y también mis sinceras felicitaciones por la compleción de esa bella obra ${ }^{27}$. Un reconocimiento de su mérito puede Usted esperar más aquí que en su patria adoptiva, lo que $|2|$ también se desprende de sus apéndices. Pero eso son solo restricciones temporarias y Usted no se apartará por ello de la continuación de sus estudios indiano=hispánicos. $\mathrm{La}$ lingüística general va a obtener mucha utilidad del diccionario. La historia de palabras como tanda resulta instructiva en el más alto grado ${ }^{28}$. El vasco chanda (ť̌anda) - según Azkue guip., dudosamente vizc. - = turno, vez, se convierte en una forma de diminutivo, para ser $* \tilde{t a n d a}(\tilde{\mathrm{t}}=\mathrm{tj})$, de donde es tomada para el esp. tanda 1) roncal. Sant. = muchedumbre, rebaño 2) rom. $|3|=$ plazo, tandaka = á plazos (p. ej. pagar á plazos, payer à termes). Mis más atentos saludos

H Schuchardt

27 Schuchardt poseía una copia del Diccionario etimolójico de las voces chilenas derivadas de lenguas indijenas americanas (Lenz 1910; Weiss 1986a: 60), y aún puede consultarse en la biblioteca universitaria de Graz. La copia de Schuchardt (catalogada como I 222511) contiene una dedicatoria manuscrita de Lenz a Schuchardt y algunas notas marginales probablemente escritas por el propio Schuchardt. Por ejemplo, Lenz había escrito en una nota al pie: "Se llama lenguaje criollo un idioma formado por voces europeas con gramática de pueblo salvaje o semicivilizado" (Lenz 1910: 41). El comentario al margen dice "nein!" [no].

28 Cf. Lenz (1910: 707-710). 


\subsubsection{Carta 04-06398}

Corresp. No. 04

Bibl. No. 06398

Tipo: carta manuscrita de Lenz a Schuchardt

Lugar: Hamburgo, Alemania

Fecha: 24 de junio de 1921

Hamburg, Ibero-amerikanisches Institut, Rotenbaumchaussee 36.

14. Juni 1921.

Herrn Professor Dr. Hugo Schuchardt, Universität, GRAZ. Steyermark.

\section{Sehr geehrter Herr Kollege!}

Ich befinde mich seit einigen Wochen auf Urlaub in Deutschland $u$. habe die Reise mit einem holländischen Frachtdampfer „Almelo“ gemacht. Die Compagnie ist nicht empfehlenswert, da viele Holländer, darunter der Kapitän u. der erste Offizier durchaus nicht deutschfreundlich waren. Die Hygiene und Verpflegung war recht mangelhaft. Aber ich bin wohl der einzige Passagier, der Vorteil gehabt hat von der Reise. Die ersten 5 Wochen habe ich Holländisch gelernt und die letzten drei, von Curazao an, das Negerkreolisch der Insel, genannt „Papiamento“, eine tolle Misch[un]g von Portugiesisch, Spanisch und Holländisch mit flexionsloser Grammatik. Der Koch an Bord war ein Neger aus Curazao, und es waren noch drei teils schwarze, teils weisse Genossen an Bord, die auch Papiamento als Muttersprache anerkannten. Ich möchte nun gern wissen, ob Ihnen als Sachverständigen etwas von wissenschaftlicher Bearbeitung dieser Sprache bekannt ist. Ich hatte Ihre Kreolische Studien leider nicht an Bor[d,] sondern in Santiago gelassen; habe aber heute, bei flüchtiger Durchsicht auch nichts darin gefunden. Ich habe an 50 MSseiten Dokumente. Der Neger hat mir eine volkstümliche Geschichte, u. eine längere Geschichte, die er in einem Buch gelesen hat, sowie einige Volklieder und eigene Produkte in Prosa und Versen (!!) aufgeschrieben. Ich habe mir das vorlesen lassen, phonetische und andere Notizen dazu gemacht und glaube es lohnt der Veröffentlichung. Es gibt in der Sprache eigene Litteratur. Einen Abriss von elementarer Grammatik, ein inhaltlich geordnetes Wörterbuch und einen Orthographietraktat (!) Mischung von holländischer u. spanischer Schreibung habe ich in Curazao gekauft, andere Sachen bestellt. So einen Katechismus, den ein deutscher Kapuziner vom Bischoff bekommen hatte. Es erscheint auch eine Zeitung in Papiamento. Es ist also eine wirkliche lebende Sprache und nicht nur 
ein Verkehrsmittel zwischen zwei Fremden. Ich wäre Ihnen sehr dankbar, wenn Sie mir Litteraturangaben irgendwelcher Art machen könnten, auch im allgemeinen über Negerspanisch oder holländische Einflüsse in Westindien. Wir haben ja in Chile seit 1915 überhaupt keine europäische Publikazionen mehr bekommen und seit 1908 nicht einmal die Zft. f. Rom. Phil. und Romania gehabt. Ich benutze meine Zeit hier in Hamburg um das nachzuholen. Hoffentlich kann ich bis September in Deutschland bleiben und dann bis Februar nach Spanien gehen. Aus Ihrer Zusendung von neueren Veröffentlichungen, die ich Mitte Februar kurz vor meiner Abreise erhielt, schliesse ich, dass Sie meine Oración y sus Partes aus Spanien bekommen haben. Ich möchte wohl wissen, was Sie dazu sagen. Mit den besten Wünschen für Ihr Wohlergehen wartet sehnlichst auf Antwort (wenn auch noch so kurz) Ihr ergebenster

RLenz

Ich bleibe bis Ende Juni hier; obige Adresse wird aber auch weiterhin genügen.

\section{Traducción}

Hamburgo, Instituto Ibero-Americano,

Rotenbaumchaussee 36.

14. Juni 1921.

Sr. Profesor Dr. Hugo Schuchardt:

Universidad, GRAZ. Steyermark.

Muy estimado Señor colega!

Me encuentro desde hace algunas semanas de vacaciones en Alemania, y he hecho mi viaje en un vapor de carga holandés, el "Almelo". La Compañía no es recomendable, puesto que muchos holandeses, entre ellos el Capitán y el Primer Oficial, no eran en ningún modo amigos de lo alemán. La higiene y cuidado eran realmente deficientes. Pero seguramente soy el único pasajero que obtuvo alguna ventaja del viaje. Las primeras 5 semanas aprendí holandés y las últimas tres, ya desde Curazao, el criollo negro de la isla, llamado "Papiamento", una formidable mezcla de portugués, español y holandés con gramática no flexiva. El cocinero de a bordo era un negro de Curazao, y había otros tres compañeros a bordo, en parte negros, en parte blancos, que también reconocían tener el papiamento como lengua materna. Ahora bien, quisiera saber si Usted, como experto en la materia, conoce alguna investigación científica sobre esta lengua. Desgraciadamente, no tenía a bordo sus Kreolische Studien, sino que los había dejado en Santiago; sin 
embargo hoy, en un rápido repaso, tampoco encontré nada en ellos. Tengo unas 50 páginas de documentos manuscritos. El negro transcribió para mí una historia popular, y una historia más larga que había leído en un libro, así como algunas canciones populares y productos propios en prosa y versos (!!). Le pedí que me los leyera en voz alta, hice notas fonéticas y de otro tipo acerca de eso, y creo que merece la publicación. Hay una literatura propia en la lengua. En Curazao compré un compendio de gramática elemental, un diccionario ordenado por contenido y un tratado de ortografía (!) mezcla de escritura holandesa y española, y encargué otras cosas. Así un catecismo que un capuchino alemán había recibido del Obispo. También se publica un periódico en papiamento. Es entonces una lengua realmente viva y no solamente un medio de intercambio entre dos extraños. Le estaría muy agradecido si me pudiera proporcionar referencias bibliográficas de algún tipo, también en general sobre el español negro o las influencias holandesas en las Indias Occidentales. En Chile desde 1915 que no recibimos ya absolutamente ninguna publicación europea y desde 1908 ni siquiera hemos tenido el Zft. f. Rom. Phil. y Romania ${ }^{29}$. Utilizo mi tiempo aquí en Hamburgo para remediar eso. Espero poder permanecer en Alemania hasta septiembre y luego ir en febrero a España. De su envío de nuevas publicaciones, que recibí a mediados de febrero, poco antes de mi partida, deduzco que ha recibido desde España mi Oración y sus Partes ${ }^{30}$. Me gustaría saber qué dice Usted de eso. Con los mejores deseos de bienestar para Usted, espera ansiosamente respuesta (aunque sea breve) su más atento

RLenz

Me quedo aquí hasta fin de junio; la dirección de arriba va a ser igualmente válida luego.

\subsubsection{Carta 05-06399}

Corresp. No. 05

Bibl. No. 06399

Tipo: carta manuscrita de Lenz a Schuchardt

Lugar: Hamburgo, Alemania

Fecha: 25 de junio de 1921

29 La revista Zeitschrift für romanische Philologie fue fundada por Gustav Gröber (18441911 ) en 1877, y Romania fue fundada en 1872 por Gaston Paris (1839-1903), cf. supra.

30 La oración y sus partes (Lenz 1920) no es mencionado en Weiss (1986a), pero la copia en la biblioteca de la Universidad Graz (I 320531) lleva el ex-libris de Schuchardt. 
Hamburg, 36. Ibero-amerikanisches Institut.

Rotenbaumchaussee

25. Juni 1921.

Herrn Geheimrat Prof. Dr. Hugo Schuchardt, GRAZ, Joh.-Fuxgasse 30.

\section{Sehr geehrter Herr Kollege!}

Nehmen Sie meinen herzlichsten Dank für die freundliche Zusendung der Litteraturangaben über das Papiamento. Ich habe noch eine Reihe anderer Angaben aus der Encyclopaedie van Nederlandsch West-Indië (ed. Benjamins u. Sneileman, Leiden, 1914-17) herausgefunden. Es scheint aber dass eine wissenschaftliche Untersuchung noch nicht existiert.

Wenn Sie mir Ihre doppelten Exemplare zur Verfügung stellen wollen, so werde ich Ihnen sehr dankbar sein. Die obige Adresse genügt, auch wenn ich unterd[esse]n weitergereist sein sollte. Aus Ihrer Schrift über die Samarakkasprache [sic] ersehe ich, dass grosse Ähnlichkeit im Verfahren zwischen diesem u. dem Papiamento besteht; nur dass eben hier die Wörter wesentlich spanisch sind. Ich glaube, dass meine Texte einige Bedeutung haben, weil es eben die wirklich von dem Neger ohne gelehrten Einfluss gesprochene $u$. geschriebene Sprache ist, worüber man bei den Übersetzungen nie sicher sein kann.

Heute halte ich hier in der Universität einen Vortrag über "Die Erziehung des deutschen Kindes im spanischen Ausland", natürlich speziell über die chilenischen Verhältnisse. Im Juli gehe ich wahrscheinlich mit meiner Familie (Frau, Tochter u. zwei Enkelinnen) nach Schreiberhau. Im August nach Bonn, Frankfurt etc. u. zum Oktober nach Spanien. Mit den besten Wünschen für Ihr Wohlergehen und nochmals bestem Dank verbleibe ich Ihr ergebenster

\section{RLenz}

Gatchet habe ich schon eingesehen. Er bietet nichts wesentliches. Ich hoffe von Bethencourt aus Curazao weiteres Material zu erhalten.

\section{Traducción}

Sr. Consejero Privado Prof. Dr. Hugo Schuchardt, GRAZ, Joh.-Fuxgasse 30. 


\section{¡Muy estimado colega!}

Reciba usted mi más sentido agradeciminento por el amistoso envío de las referencias bibliográficas sobre el Papiamento $^{31}$. Además he descubierto toda una serie de referencias en la Encyclopaedie van Nederlandsch WestIndië (ed. Benjamins u. Sneileman, Leiden, 1914-17). Parece sin embargo que no hay aún una investigación científica sobre el tema.

Si quisiera poner a mi disposición sus ejemplares duplicados, le estaría muy agradecido. A partir de su escrito sobre la lengua samaraccan ${ }^{32}$ puedo colegir que existe una gran similitud en el proceder entre esta y el papiamento; solo que en este caso las palabras resultan ser esencialmente españolas. Creo que mis textos tienen un sentido porque se trata justamente de la lengua hablada y escrita por el negro sin influencia culta, de lo cual no se puede estar nunca seguro en el caso de las traducciones.

Hoy daré una conferencia aquí en la Universidad sobre "La educación del niño alemán en el extranjero español", naturalmente en especial acerca de la situación en Chile. En julio es probable que vaya con mi familia (mujer, hija y dos nietas) a Schreiberhau. En agosto a Bonn, Frankfurt, etc. y para octubre a España. Con los mejores deseos de bienestar, y nuevamente muchas gracias, lo saluda su servidor,

\section{RLenz}

A Gatchet ya lo leí ${ }^{33}$. No ofrece nada esencial. Espero recibir más material de Curazao de parte de Bethencourt ${ }^{34}$.

31 En la introducción a El Papiamento, Lenz menciona que Schuchardt le había enviado "una lista de 31 títulos de publicaciones en papiamento, o estudios sobre esta lengua que poseía, editados entre 1843 i 1891" (Lenz 1928: 10). También parece estar citando una carta de Schuchardt cuando escribe: "Respecto del Papiamento escribió Schuchardt: 'Yo mismo he mencionado el papiamento sólo ocasionalmente. Creía siempre, que, siendo suficientemente conocido, merecería algún día un tratamiento serio de alguna otra persona. Nunca lo he perdido de vista"” (Lenz 1928: 11).

32 Cf. Schuchardt (1914a [HSA 656]).

33 Albert Samuel Gatschet (1832-1907) publicó en su artículo “The Aruba Language and the Papiamento Jargon" (Gatschet 1885) algunas muestras -entre otras- de papiamento recogidas por Alphonse Pinart (1852-1911). Ambos mantenían correspondencia con Schuchardt (Wolf 1993).

34 Probablemente el editor “A. Bethencourt é Hijos” de Curazao. 


\subsubsection{Postal 06-06400}

Corresp. No. 06

Bibl. No. 06400

Tipo: postal manuscrita de Lenz a Schuchardt

Lugar: Oberschreiberhau, Alemania

Fecha: 8 de julio de 1921

8.VII.1921

Oberschreiberhau i. Rsgb.

Landhaus Lindengarten (144)

Sehr verehrter Herr Kollege!

Nehmen Sie meinen herzlichsten Dank für die reichhaltige Sendung der Papiamentoschriften, die um so wertvoller für mich sind je älter ihr Datum. $50 \mathrm{u}$. 70-Jahre alte amerik. Bücher auftreiben zu wollen, ist fast immer vergebens. Die rein holländ. Orthographie des alten Putman ist phonetisch wertvoll, und die Imitacion di Cristu ist doch immerhin geläufigere Sprache als die Katechismen. Ich bin neugierig auf die ganz modernen Sachen, die ich von Curazao erwarte.

Unterdessen sitze ich mit meiner Familie in diesem lieblichen Erdwinkel, nachdem ich im vorigen Monat in Hamburg das Phonet. Laboratorium, das afrik. Seminar (Meinhof), das romanische (Schädel, Krüger etc) u. das Völkermuseum etc. ausgeschunden habe. Es ist ein merkwürdig Ding nach 35 Jahren mit Jugendfreunden zusammenzukommen; hier z. B. Wilhelm Bölsche! Dazu all die neuen Bücher über vergl. Sprachwissenschaft. Habe eben H. Winkler, Altaische Völker-u. Sprachenwelt durchgeackert. Zur Ausarbeitung des Papiamento werde ich aber wohl erst nächstes Jahr in Chile kommen. Nochmals besten Dank und die besten Wünsche für Ihr Wohlergehen. Ihr ergebenster

R Lenz

Traducción

8.VII.1921

Oberschreiberhau i. Rsgb.

Casa de campo Lindengarten (144)

¡Muy venerado colega! 
Le doy las gracias de todo corazón por el provechoso envío de los escritos en papiamento, que tanto más valiosos son para mí cuanto más antigua su data. Querer dar con libros americanos de hace 50 y 70 años es casi siempre en vano. La ortografía puramente holandesa del viejo Putman es fonéticamente valiosa, y la Imitacion di Cristu se encuentra después de todo en una lengua más corriente que la de los catequismos. Siento curiosidad por las cosas más modernas, que espero de Curazao ${ }^{35}$.

Entretanto, me encuentro instalado con mi familia en este adorable rincón del planeta, luego de haber, el mes pasado, despellejado en Hamburgo el Laboratorio fonético, el Seminario africano (Meinhof) ${ }^{36}$, el románico (Schädel, Krüger etc) ${ }^{37}$ y el Museo de los Pueblos etc. Es una cosa notable

35 En su bibliografía del papiamento, Lenz menciona también entre sus fuentes las publicaciones que estaban en poder de Schuchardt (Lenz 1928: 18-29). De estas 25 fuentes, resalta siete escritos enviados a él definitivamente, porque Schuchardt aparentemente poseía duplicados de los mismos (cf. Lenz 1928: 18-21). Las publicaciones son:

- I. H. S.. 1851. Keda lamantar i reza! Oen present pa moetsja nan arieba dia di nan promeer santa komoenion. Santa Rosa.

- Putman, J. J.. 1852. Bida di Hesoe Kriestoe. Santa Rosa.

- 1853a. Gemeenzame Zamenspraken, behoorende by de: Proeve eener Hollandsche Spraakkunst, ten gebruike der algemeene armenschool, in de gemeente van de H. Rosa, op Curaçao. Tweede stukje door J. J. Putman. Santa Rosa.

- 1853b. Meditasjon arieba soefrimeentoe di noos Senjoor Hesu Kriestoe. Historia, exemplo i orasjon, pa J. J. Putman, Pastoor; i soe roeman, Joanna Adr. Putman, fundadora di skool pa moetsja moheer pober na Sta. Rosa. Imprimier na Santa Rosa.

- 1853c. Oen Floor, ki J. J. Putman ta boeta arieba sepoelkro di soe roeman stimaar Joanna Adriana Putman. Imprimier na Santa Rosa.

- 1876. Guia para los españoles hablar papiamento, i viceversa, para que los de Curazao. Imprenta del Comercio.

- 1879. Canticanan Religiosa. Segunda edicion, Curazao.

- 1882. Cuater Boeki di Imitacion di Cristoe. Curazao. Imprenta de la Librería.

Los autores de esta contribución no están al tanto de una colección de materiales del papiamento del propio Schuchardt. En Wolf(1993), no se da indicación alguna con respecto a ningún manuscrito. Hasta donde pueden ver los autores, hay solo unas pocas fuentes impresas en papiamento en Weiss (1986a) o en el fichero digitalizado de la Biblioteca de la Universidad de Graz, donde no figura ninguna de las publicaciones listadas por Lenz. Los textos impresos en papiamento preservados en la Biblioteca de la Universidad de Graz son Nederlandschpapiamentsch-spaansch woordenboekje (Ewijk 1875, catalogado como I 221792) y una Woordenlyst en zamenspraak (1876, catalogada como I 22189). Ambos volúmenes revisten el ex-libris de Schuchardt y también son citados por Lenz (1928).

36 Carl Friedrich Michael Meinhof (1857-1944) fue un africanista alemán. En 1909 fue nombrado Catedrático de lenguas africanas en el Kolonialinstitut de Hamburgo. A partir de 1933 fue miembro del NSDAP.

37 Bernhard Schädel (1878-1926) fundó el seminario de lenguas romance en 1911 y en 1917 el Ibero-Amerikanisches Institut de Hamburgo. En 1919 fue nombrado Profesor de 
después de 35 años reunirse con amigos de la juventud; aquí por ej. Wilhelm Bölsche! ${ }^{38}$ Además de eso, todos los nuevos libros sobre lingüística comparada. He vadeado incluso el de H. Winkler, Altaische Völker-u. Sprachenwelt ${ }^{39}$. Pero a la elaboración del papiamento llegaré recién el año próximo en Chile. Una vez más muchas gracias y los mejores deseos para su bienestar. Su servidor,

R Lenz

\subsubsection{Carta 07-06401}

Corresp. No. 07

Bibl. No. 06401

Tipo: carta manuscrita de Lenz a Schuchardt

Lugar: Santiago de Chile

Fecha: April 26, 1925

Santiago de Chile, 26. April 1925.

Herrn Prof. Dr. Hugo Schuchardt,

Universität, GRAZ, Oesterreich, Austria.

Mein hochgeehrter Herr Kollege!

Vor einigen Tagen brachte mir die Post Ihren Gruss mit dem Aufsatz "Das Baskische und die Sprachwissenschaft". Ich habe das Heft mit grossem Genuss gelesen und mich sehr gefreut, dass ich in sehr vielen Punkten genau so denke wie Sie in bezug auf die allgemeine Sprachverwandtschaft und -entwicklung. Leider fühlte ich auch wieder das Unglück meiner Vereinsamung "im letzten Winkel der Welt", wo ich ausser meiner eignen Bibli[o]thek kaum ein einziges wissenschaftliches Buch zu sehen bekomme. Seit dem Kriege habe ich keine wissenschaftlichen Zeitschriften aus Europa bekommen und im Instituto Pedagógico gieb[t] es solche überflüssigen Dinge wie Gröber's Zeitschrift und Romania schon seit 1909 nicht mehr. Von den von Ihnen zitierten Büchern habe ich nur Meillet und Vendryes. Das

Filología Romance. Fritz Krüger (1889-1974) sucedió a Schädel como catedrático a partir de 1928. En 1937 se sumó al NSDAP. Después de 1945 emigró a Argentina (cf. Hausmann 2016).

38 Probablemente el escritor Wilhelm Bölsche (1861-1939), que estudió en Bonn en la misma época que Lenz y fue parte luego del Friedrichshagener Dichterkreis [Círculo de poetas de Friedrichshagen] en Berlín.

39 Esto es, Die Altaische Völker- und Sprachenwelt (Winkler 1921). 
Baskische hat mich seit lange $[\mathrm{m}]$ interessiert, vor allem, weil ich irgendwo gelesen hatte, dass seine Grammatik mit den amerikanischen Sprachen Ähnlichkeit haben sollte. Ich habe eine alte Grammaire von M. F. Lécluse (Bayonne, 1874). Als ich in Spanien war (Dezember 1921 bis März/22) habe ich Campion: Gramática bascongada und Lopez Mendizabal Diccionario castellano-euskera gekauft. Azkue war nicht zu haben! Damit habe ich mich auf meiner Heimfahrt nach Chile beschäftigt.

Bei meiner Rückkehr hatte ich das Unglück (!) meine Ernennung zum Rector des Instituto Pedagógico vorzufinden, ohne dass man mich vorher gefragt hätte. Nach ein paar Monaten gräuliche[r] $|2|$ Arbeit, es waren gerade Studentenstreiks, wurde ich von meinem Sekretär um etwa 10000 Pesos bestohlen und ich legte den Poste nieder durch all den Ärger gründlich ruiniert, so dass ich mehrere Monate arbeitsunfäig [sic] war. So kam es, dass ich überhaupt erst nach Ablauf des Jahres 1923 im Januar bis März /24 während der Ferien anfangen konnte mich mit meinem lieben Papiamento von Curazao zu beschäftigen. Während des Jahres hatte ich dann durch Bau in meinem Hause allerhand Extraarbeiten. Die Vorlesungen (18 Stunden wöchentlich!) machten mich müde und ich konnte erst diesen Januar bis März wieder weiterarbeiten. Jetzt habe ich die Grammatik so ziemlich fertig; es fehlt mir nur noch die Phonologie der eigentlichen Kreolenwörter. Wie viel ich dabei Ihren Kreolischen Studien verdanke, und den Aufsätzen in Gröbers Zft. XII, XIII, XXXIII und Romania XI, XX werden Sie hoffentlich noch in diesem Jahre lesen können. Was mich am meisten interessiert, ist, dass das Papiamento wohl die einzige Kreolsprache ist, die sich von der Negerkultur, dem Negerportugiesischen, bis zur wirklichen Kultursprache für europäisch Gebildete heraufgearbeitet hat und dabei doch ihre Negergrammatik beibehalten hat. Ich habe noch eine ganze Anzahl moderner Publikazionen aus Curazao erhalten darunter auch E Testament nobo uitgegeven door het Nederlandsc[h] Bijbelgenootschap, Amsterdam, 1916. Ich möchte mit meiner Arbeit (es sind bis jetzt etwa 150 Druckseiten) den Philologen Gelegenheit geben eine Kreolensprache wirklich praktisch kennen zu lernen; denn das Papiamento ist ja für jeden der Spanisch kann, in ein paar Minuten verständlich, was man von dem Negro-english Testament (London, 1901) nicht sagen kann. Es ist das einzig brauchbare Volapük, das beweist, dass die Grammatik der idg. Sprachen vom Teufel erfunden [wurde], zur Strafe für Babel! Nun, nochmal herzlichen Dank für alles, was ich Ihnen verdanke! Mit herzlichstem Gruss, Ihr ergebenster

\section{RLenz}

[escrito a mano en el margen izquierdo] Ich hoffe in den nächsten Wochen pensioniert zu werden und dann noch fleißig zu sein! 


\section{Traducción}

Santiago de Chile, 26 de abril de 1925.

Sr. Prof. Dr. Hugo Schuchardt, Universidad, GRAZ, Austria.

Mi estimadísimo colega!

Hace algunos días el correo me trajo su saludo con el ensayo "El vasco y la lingüística" ${ }^{40}$. He leído la separata con gran placer, y me ha alegrado mucho ver que en muchos puntos pienso exactamente como Usted con respecto al parentesco y desarrollo lingüístico general. Desgraciadamente, pude sentir nuevamente mi aislamiento "en el último rincón del mundo", donde a excepción de mi propia biblioteca apenas llego a ver algún libro científico. Desde la guerra no he recibido más publicaciones científicas de Europa y en el Instituto Pedagógico cosas superfluas como la revista de Gröber y Romania no las hay ya desde 1909. De los libros citados por Usted solo tengo los de Meillet y Vendryes. El vasco me interesa desde hace tiempo, sobre todo, porque leí en algún lado que su gramática tendría similitud con las lenguas americanas. Tengo una vieja Grammaire de M. F. Lécluse (Bayona 1874). Cuando estuve en España (desde diciembre de 1921 hasta marzo de 1922) compré la Gramática bascongada de Campion y el Diccionario castellanoeuskera de Lopez Mendizabal ${ }^{41}$. ¡Azkue no se conseguía! Con ellos me entretuve en mi viaje de regreso a Chile.

A mi regreso tuve el infortunio (!) de encontrarme con mi nombramiento como Rector del Instituto Pedagógico, sin que nadie me hubiera preguntado antes. Luego de un par de meses de trabajo sórdido, ya que había en ese momento huelgas estudiantiles, unos 10000 pesos me fueron robados por mi secretario, y renuncié al cargo, completamente arruinado por todo el disgusto, de modo tal que quedé incapacitado para el trabajo por varios meses. Así fue que solo después de expirado el año 1923, entre enero y marzo del 24 pude empezar durante las vacaciones a ocuparme de mi querido papiamento de Curazao. Durante el año tuve luego trabajo extra debido a obras en mi casa. Las clases ( 18 horas semanales!) me cansaban y solo en este enero, hasta marzo, pude retomar el trabajo nuevamente. Ahora tengo la gramática bastante lista; solamente me resta la fonología de las palabras auténticamente

\footnotetext{
40 Cf. „Das Baskische und die Sprachwissenschaft“ (Schuchardt 1925a).

41 Probablemente la Gramática de los cuatro dialectos literarios de la lengua euskara (Campión 1884) y el Diccionario castellano-euzkera (López Mendizábal 1916).
} 
criollas. Cuánto agradezco en este punto sus Kreolischen Studien y los artículos en la revista de Gröber XII, XIII, XXXIII y Romania XI, XX ${ }^{42}$, espero que pueda llegar a leerlo aún este año. Lo que más me interesa es que el papiamento parece ser la única lengua criolla que ha progresado desde la cultura negra, el portugués negro, hasta ser una verdadera lengua de cultura para europeos ilustrados, conservando no obstante su gramática negra. He recibido una buena cantidad de publicaciones modernas de Curazao, entre ellas también E Testament nobo uitgegeven door het Nederlandsc[h] Bijbelgenootschap, Amsterdam, 1916. Quisiera con mi trabajo (hasta ahora son unas 150 páginas) dar la oportunidad a los filólogos de conocer realmente de manera práctica una lengua criolla; puesto que el papiamento es comprensible en un par de minutos para cualquiera que sepa español, lo que no puede decirse del Testamento negro-inglés (London, 1901). Es el único Volapük útil, que demuestra que la gramática de las lenguas indogermánicas fue inventada por el diablo, ¡como castigo por Babel! En fin, una vez más, gracias de todo corazón ipor todo lo que debo a Usted! Con el más cordial saludo, su servidor,

RLenz

[escrito a mano en el margen izquierdo] ¡Espero pasar a retiro en las próximas semanas, y luego mantenerme aplicado al trabajo!

\subsubsection{Carta 08-06402}

Corresp. No. 08

Bibl. No. 06402

Tipo: carta manuscrita de Lenz a Schuchardt

Lugar: Santiago de Chile

Fecha: 31 de marzo de 1926

Santiago de Chile, 31. März 1926.

Herrn Professor Dr. Hugo SCHUCHARDT,

42 Cf. los "Kreolischen Studien" I-IX (Schuchardt 1882a, 1882b, 1883, 1884a, 1884b, 1884 c, 1888d, 1888e y 1890), "Beiträge zur Kenntnis des kreolischen Romanisch" I-VI (Schuchardt 1888a, 1888b, 1888c, 1889a, 1889b y 1889c), "Die Lingua franca" (Schuchardt 1909) y "Sur le créole de la Réunion" (Schuchardt 1882c). El artículo en Romania, vol. 20 probablemente sea un error de parte de Lenz. En Lenz (1928: 27), menciona también -además de las obras de Schuchardt-el trabajo del antiguo discípulo de Schuchardt, Alphonse Dietrich, "Les parlers créoles des Mascareignes" (Dietrich 1891), que había sido publicado de hecho en Romania 20 (cf. Krämer 2014). 
Johann Fuxgasse 30, GRAZ, Austria. Oesterreich.

Mein hochgeehrter Herr Kollege!

Mitte dieses Monats habe ich Ihre Abhandlung: "Der Individualismus in der Sprachwissenschaft" erhalten und mit grösstem Genuss und Nutzen gelesen. Herzlichen Dank! auch für die Andeutung meiner Papiamentoarbeiten. Diesselben sind leider noch immer nicht im Druck; aber ich hoffe, sie in diesem Jahre so weit zu bringen. Seit Juli vorigen Jahres bin ich pensioniert; habe aber meine Kurse Castellano Tercer Año noch bis zu Ende geführt, damit meine Schüler noch vor mir Examen machen könnten. In den Ferien, Ende Dezember bis Anfang März war ich in "der chilenischen Schweiz", in Puerto Varas am Llanquihuesee, der einzigen Gegend im Süden Chiles, die ich noch nicht kannte. Dort wird mehr Deutsch als Spanisch gesprochen! Vor 70 Jahren haben deutsche Kolonisten dort die Urwälder gerodet und in Kulturland verwandelt. Leider fand ich dort auch keinen einzigen Indianer mehr und hatte meine Estudios Araucanos umsonst mit genommen. Sonst hatte ich kein einziges Buch bei mir und habe mich mit Spaziergängen, Fahrten auf dem See, Baden und dergl. einmal gründlich ausgeruht. Ich hoffe nun also bald mein Papiamento beenden zu können. Dann hoffe ich noch eine zusammenfassende spanische Abhandlung über den chilenischen Volksdialekt und eine analytische Mapuchegrammatik zu schreiben. Ich hab[e] mir Sie und Wilhelm Wundt als Vorbilder genommen um nach dem 63. Jahre noch was nützliches zu tun. ¡Ojalá lo alcance! Vor einigen Tagen sandte ich Ihnen meine Schrift: "Sobre el estudio de idiomas" worin ich auch Individuelles behandle. Viele Grüsse und beste Gesundheit! Ihr dankbarer

Rlenz

\section{Traducción}

Santiago de Chile, 31. März 1926.

Herrn Professor Dr. Hugo SCHUCHARDT,

Johann Fuxgasse 30, GRAZ, Austria. Oesterreich.

¡Mi estimadísimo colega!

A mitad de este mes he recibido su trabajo: "Der Individualismus in der Sprachwissenschaft" [El individualismo en la lingüística], y lo he leído con enorme gusto e interés. ¡Muchísimas gracias! También por la alusión 
a mis trabajos sobre el papiamento ${ }^{43}$. Los mismos no se encuentran aún, lamentablemente, en prensa, pero espero llevarlos a término en el curso de este año. Desde julio del año pasado estoy jubilado; no obstante, he llevado aún a término mis cursos de Castellano de Tercer Año, de modo tal que mis alumnos pudieran dar examen conmigo todavía. En las vacaciones, desde fines de diciembre hasta comienzos de marzo, estuve en la "Suiza chilena", en Puerto Varas junto al lago Llanquihue, la única comarca del sur de Chile que aún me era desconocida. ¡Allí se habla más alemán que español! Hace 70 años, los colonos alemanes desmontaron los bosques vírgenes y los transformaron en tierras de cultivo. Desgraciadamente, no encontré allí ningún indio más, por lo que llevé en vano conmigo mis Estudios Araucanos. Más allá de eso, no tenía un solo libro conmigo, y me despejé por completo con caminatas, paseos en el lago, baños y cosas por el estilo. Ahora sí, espero poder terminar pronto mi Papiamento. Luego espero escribir un trabajo de síntesis sobre el dialecto popular chileno y una gramática analítica mapuche. Los he tomado a Usted y Wilhelm Wundt como modelos para hacer algo útil aún después de los 63 años. ¡Ojalá lo alcance! Hace algunos días le envié mi escrito: "Sobre el estudio de idiomas" donde también trato temas individuales ${ }^{44}$. Muchos saludos y mucha salud! Su agradecido

\section{Rlenz}

\subsubsection{Carta 09-06403}

Corresp. No. 09

Bibl. No. 06403

Tipo: carta manuscrita de Lenz a Schuchardt

Lugar: Santiago de Chile

Fecha: 17 de noviembre de 1926

43 Schuchardt (1925b: 14) establece que la importancia de las lenguas criollas para la lingüística general ha sido gradualmente aceptada y agrega en una nota a pie de pagina que las lenguas criollas "sind zum großen Teil schon fixiert, ja zu einer gewissen Literatur gediehen, besonders das Papiamento von Curaçao, von dem wir übrigens eine ausführliche Darstellung aus bewährter Hand zu hoffen haben" [estan en gran parte ya fijadas, hasta dedicadas a una cierta literatura, especialmente el papiamento de Curazao, sobre el cual esperamos tener una exposición detallada de una mano competente] (Schuchardt 1925b: 14-15). Sin embargo, no menciona el nombre de Lenz.

44 El artículo "Sobre el estudio de idiomas" (Lenz 1919) no aparece mencionado en Weiss (1986a), pero está listado en el fichero digitalizado de la Biblioteca de la Universidad de Graz (catalogado como I 220.182). Esta copia también tiene el ex-libris de Schuchardt. 
Santiago de Chile, 17. November 1926.

Herrn Professor Dr. Hugo SCHUCHARDT,

Johann Fuxgasse 30, GRAZ, Austria.

Mein hochverehrter Herr Kollege!

Ich hoffe, dass Sie meine beiden Briefe vom 26/4/25 und vom 31/3/26 erhalten haben, in denen ich Ihnen für die Zusendung von "Das Baskische und die Sprachwissenschaft" und "Der Individualismus in der Sprachwissenschaft" bestens dankte.

Nun endlich erhalte ich den Separatabzug des ersten Teile[s] meiner Papiamento-arbeit [handschriftlich eingefügt] und sende ihn gleichzeitig als Drucksache. Das ganze wird erst in einem Jahre fertig werden, da die Anales de la Universidad jetzt nur noch alle drei Monate erscheinen "por falta de fondos!" Der zweite Teil mit der Grammatik wird wohl in drei Wochen folgen.

Wie Sie sehen werden, bin ich ganz ihrer Ansicht über das Kreolische: es ist "gramática mínima" aber nicht "africana".

Ich hoffe, dass Sie die Negermaterialien mit Genuss lesen werden und sich nicht stossen werden, wenn Sie die beiden grossen Erzählungen lesen, weil sie nicht ganz "fein anständig["] sind. In Curazao wird das vielleicht Anstoss erregen; deshalb liess ich die Veröffentlichung ohne Übersetzung bis zum Schluss.

Nun wünsche ich Ihnen beste Gesundheit; das ist ja das Einzige, was wir alten Leute noch brauchen.

Mit besten Grüssen Ihr dankbarer

Rlenz

\section{Traducción}

Santiago de Chile, 17 de noviembre de 1926.

Sr. Profesor Dr. Hugo SCHUCHARDT, Johann Fuxgasse 30, GRAZ, Austria.

¡Mi venerado colega!

Espero que haya recibido mis cartas del $26 / 4 / 25$ y del $31 / 3 / 26$, en las que le expreso mi mayor agradecimiento por "Das Baskische und die 
Sprachwissenschaft" [El vasco y la lingüística] y "Der Individualismus in der Sprachwissenschaft" [El individualismo en la lingüística ${ }^{45}$.

Finalmente he recibido la separata de la primera parte de mi trabajo sobre el papiamento [con anotaciones manuscritas] y lo envío al mismo tiempo como impreso ${ }^{46}$. El trabajo completo va a estar listo recién en un año, ya que los Anales de la Universidad ahora aparecen sólo trimestralmente "ipor falta de fondos!" La segunda parte con la gramática seguirá, espero, en tres semanas.

Como Usted podrá ver, soy completamente de su misma opinión en cuanto al criollo: es "gramática mínima" pero no "africana" 47.

Espero que lea con gusto los materiales de los negros y que no le resulte engorrosa la lectura de los dos largos relatos, puesto que no son muy "finos y decentes". En Curazao resultaría ofensivo, por eso dejé la publicación sin traducción hasta el final.

En fin, le deseo la mejor salud, que es lo único que nosotros, los viejos, aún necesitamos.

Con afectuosos saludos de su agradecido

Rlenz

\section{REFERENCIAS BIBLIOGRÁFICAS}

1876. Guia para los españoles hablar papiamento, $i$ viceversa, para que los de Curazao. Imprenta del Comercio.

1876. Woordenlyst en zamenspraak in de Curaçaosche landstaal door N. Lista di palabranan $i$ kombersajoon na leenga di Corsouw. Curaçao: Neümann.

45 Ver cartas 07-06401 y 08-06402.

46 Antes de su publicación íntegra en libro, el trabajo de Lenz sobre el papiamento apareció en cinco partes como "El Papiamento, la lengua criolla de Curazao (la gramática más sencilla)" en los Anales de la Universidad de Chile de 1926 (pp. 694-768, 1021-1090) y 1927 (pp. 288-327, 366-412, 888-989). No se pudo hallar referencia alguna a las separatas enviadas por Lenz ni en Weiss (1986a), ni tampoco en el fichero digitalizado de la Biblioteca de la Universidad de Graz, ni en Wolf (1993). Tampoco la obra completa, que fue publicada como El papiamento. La lengua criolla de Curazao. La gramática más sencilla (Lenz 1928), está presente en la Biblioteca de la Universidad de Graz.

${ }_{47}$ Cf. Lenz (1928: 14): "Evidentemente los niños de las familias cultas oían siempre este lenguaje en boca de la servidumbre i aprendieron a espresarse más fácilmente en esta jerga infantil con gramática minima que en los idìmas flexivos complicados de sus padres." 
1879. Canticanan Religiosa. Segunda edicion, Curazao.

1882. Cuater Boeki di Imitacion di Cristoe. Curazao. Imprenta de la Librería.

Araujo, F. 1890. Recherches sur la phonétique espagnole. Phonetischen Studien 3: 309-344. 1892. Recherches sur la phonétique espagnole. Phonetischen Studien 5: 142-169.

BACHMANN, IRIS. 2004. Wie einfach es kompliziert werden kann - Lenz. La gramática más sencilla im Schnittpunkt verschiedener sprachwissenschaftlicher Diskurse. En G. Haßler y G. Volkmann (ed.). History of Linguistics in Texts and Concepts. Münster: Nodus. 379-388.

Barros Arana, Diego. 1884-1902. Historia General de Chile. Santiago de Chile. 16 volúmenes.

Bross, Dieter. 1968. Epistolario de Rufino José Cuervo y Hugo Schuchardt. Bogotá: Publicaciones del Instituto Caro y Cuervo (= Archivo Epistolar Colombiano 2).

Cabral, Alfredo do VAlle. 1880-1881. Bibliographia das obras tanto impressas como manuscriptas, relativas á lingua tupi ou guarani tambem chamada lingua geral do Brazil. Annaes da Bibliotheca Nacional do Rio de Janeiro VIII: 143-214 [en línea]. Disponible en https://archive.org/details/bibliographiadas00cabruoft (Consulta 28/05/2020).

CAmpión, Arturo. 1884. Gramática de los cuatro dialectos literarios de la lengua euskara. Tolosa: López.

Costa Álvarez, Arturo. 1928. Una curiosidad lingüística: el papiamento. La Prensa, 20 de agosto de 1928.

Dannemann, Manuel. 2000-2001. Vida y obra de Rodolfo Lenz. Boletín de Filología 38: 331-339.

Dietrich, AlPhonse. 1891. Les parlers créoles des Mascareignes. Romania 20: 216-276.

EnNis, JuAn Antonio. 2012. Rudolf Lenz en la encrucijada criolla. Signo y Seña 22: 181-214.

Escudero, Alfonso. M. 1963. Rodolfo Lenz. Thesaurus. Boletín del Instituto Caro y Cuervo 18(2): 445-484.

EwiJk, Henricus Josephus Alexius van. 1875. Nederlandsch-Papiamentsch-Spaansch woordenboekje. Curaçao.

Gatschet, Albert S. 1885. The Aruba Language and the Papiamento Jargon. Proceedings of the American Philosophical Society 22/20(iv): 299-305 [en línea]. Disponible en http:// www.jstor.org/stable/982990 (Consulta 28/05/2020).

Gilbert, Glenn G. 1980. Introduction. En G. Gilbert (ed.). Pidgin and Creole Languages: Selected Essays by Hugo Schuchardt. Cambridge: Cambridge University Press.

Gillet, Joseph E. 1930. [Res. de:] El Papiamento. La lengua criolla de Curazao. La gramática más sencilla. Por el Dr. Rodolfo Lenz. Modern Language Notes 45(6): 413-415 [en línea]. Disponible en http://www.jstor.org/stable/2913157 (Consulta 28/05/2020).

Goldschmidt, MoRitz. 1887. Zur Kritik der altgermanischen Elemente im Spanischen. Inaugural-Dissertation zur Erlangung der Doktorwürde bei der hohen philosophischen Facultät der Rhein. Friedr-Wilh.-Universität zu Bonn. Lingen: Druck von J. L. v. d. Velde Veldmann.

1902. Germanisches Kriegswesen im Spiegel des romanischen Lehnwortes. En Beiträge zur Romanischen und Englischen Philologie. Festgabe für Wendelin Foerster zum 26. Oktober 1901. Halle a. S.: Max Niemeyer, 49-70.

HansSEn, Friedrich. 1910. Spanische Grammatik auf historischer Grundlage. Halle a. S.: Niemeyer.

Hausmann, Frank-Rutger. 2016. Fritz Otto Krüger. En K. Nonnenmacher, A. Kalkhoff y D. Bohmann (eds.). Romanistenlexikon: Verzeichnis der im deutschen Sprachraum tätig gewesenen oder aus dem deutschen Sprachraum stammenden Romanistinnen und Romanisten [en línea]. Disponible en http://lexikon.romanischestudien.de/index. php?title=Kr\%C3\%BCger,_Fritz_Otto (Consulta 28/05/2020). 
Hesseling, Dirk C. 1933. Een Spaans boek over het Papiaments. Tijdschrift voor Nederlandsche Taal- en Letterkunde 52: 40-69 [en línea]. Disponible en http://www. dbnl.org/tekst/_tij003193301_01/_tij003193301_01_0004.php (Consulta 28/05/2020).

HJelmsLev, Louis. 1939. Caractères grammaticaux des langues créoles. Actes du congrès international des sciences anthropologiques et ethnologiques. Copenhagen: Einar Munksgaard.

Hurch, Bernhard. 2007. Hugo Ernst Mario Schuchardt. En Bayerische Akademie der Wissenschaften Historische Kommission (ed.). Neue Deutsche Biographie, Band 23:. 623-624 [en línea]. Disponible en http://www.deutsche-biographie.de/pnd118611046. html (Consulta 28/05/2020).

2007-. Hugo Schuchardt Archiv [en línea]. Disponible en http://schuchardt.uni-graz. at (Consulta 28/05/2020).

2009a. Bausteine zur Rekonstruktion eines Netzwerks I: Einleitung - Prolegomena. Grazer Linguistische Studien 72: 5-17.

2009b. Ein Netzwerk des Wissens: Einige Voraussetzungen zur Profilierung der Philologie. En C. König (ed.). Das Potential Europäischer Philologien. Geschichte Leistung - Funktion (Reihe: Philologien, Bd. 1). Göttingen: Wallstein Verlag, 292-308.

2009c. Von der Peripherie ins Zentrum: Hugo Schuchardt und die Neuerungen der Sprachwissenschaft. En Karl Acham (ed.). Kunst und Wissenschaft aus Graz. Bd. 2.1. Kunst und Geisteswissenschaft aus Graz. Wien, Köln, Weimar: Böhlau, 493-510.

2011. Über "Weiberrau" und Lautgesetze. Anmerkungen zu Georg von der Gabelentz' Handbuch zur Aufnahme fremder Sprachen in baskischer Version. Beiträge zur Geschichte der Sprachwissenschaft 21: 239-262.

Hurch, Bernhard y Francesco Costantini. 2007. Die Korrespondenz zwischen Otto Jespersen und Hugo Schuchardt. En Bernhard Hurch (ed.). Hugo Schuchardt Archiv [en línea]. Disponible en: http://schuchardt.uni-graz.at/id/letters/1844 (Consulta 28/05/2020).

Hurch, Bernhard y Katrin Purgay. 2015. Die Korrespondenz zwischen Georg von der Gabelentz und Hugo Schuchardt. En Bernhard Hurch (ed.). Hugo Schuchardt Archiv [en línea]. Disponible en: http://schuchardt.uni-graz.at/id/letters/1540 (Consulta 28/05/2020).

Hurch, Bernhard y Luca Melchior. 2015. Der Briefwechsel zwischen Franz Miklosich und Hugo Schuchardt (1871-1889). Grazer Linguistische Studien 80: 79-123.

I. H. S. 1851. Keda lamantar i reza! Oen present pa moetsja nan arieba dia di nan promeer santa komoenion. Santa Rosa.

JeSPERSEN, OtTo. 1886. Til spörgsmålet om lydlove. Nordisk tidskrift for filologi. Ny Rcekke 7: 207-245.

1887. Zur Lautgesetzfrage. Internationale Zeitschrift für allgemeine Sprachwissenschaft 3: 188-216.

KRAMER, JoHANNES. 2004. Die iberoromanische Kreolsprache Papiamento: eine romanistische Darstellung. Hamburg: Buske.

KrÄMER, PhiLIPP. 2014. Die französische Kreolistik im 19. Jahrhundert. Rassismus und Determinismus in der kolonialen Philologie. Hamburg: Buske.

Labarías, María T. y Juan H. Cárdenas. 1998. Documentos auténticos de Rodolfo Lenz: catálogo crítico. Santiago: Universidad Metropolitana de Ciencias de la Educación [en línea]. Disponible en http://www.memoriachilena.cl/602/w3-article-124415.html (Consulta 28/05/2020).

Lenz, Rodolfo. 1888. Zur physiologie und geschichte der palatalen. Zeitschrift für vergleichende Sprachforschung 29: 1-59 [en línea]. Disponible https://archive.org/stream/ zeitschriftfrve35kuhngoog\#page/n15/mode/2up (Consulta 28/05/2020). 
1891. Zur spanisch-amerikanischen Formenlehre. Zeitschrift für romanische Philologie 15: 518-522 [en línea]. Disponible en http://gallica.bnf.fr/ark:/12148/ bpt6k158655/f522.image (Consulta 28/05/2020).

1892. Chilenische Studien. I. Phonetische Studien 5: 272-292 [en línea]. Disponible en https://archive.org/stream/phonetischestud01victgoog\#page/n280/mode/2up (Consulta28/05/2020).

1893a. Beiträge zur Kenntnis des Amerikospanischen. Zeitschrift für romanische Philologie 17: 188-214 [en línea]. Disponible en http://gallica.bnf.fr/ark:/12148/ bpt6k15867v/f198.image (Consulta 28/05/2020).

1893b. Chilenische Studien. II. III. Phonetische Studien 6: 18-34. [en línea]. Disponible en https://archive.org/stream/phonetischestud00vigoog\#page/n27/mode/2up (Consulta 28/05/2020).

1896. Araukanische Märchen und Erzählungen mitgeteilt von Segundo Jara (Kalvún). Valparaiso: Universo de Guillermo Helfmann. [en línea]. Disponible en http:// www.zeno.org/nid/20007822235 (Consulta 28/05/2020).

1902. Die indianischen Elemente im Chilenischen Spanisch. En Beiträge zur Romanischen und Englischen Philologie. Festgabe für Wendelin Foerster zum 26. Oktober 1901. Halle a. S.: Max Niemeyer, 1-48.

1910. Diccionario etimolójico de las voces chilenas derivadas de lenguas indijenas americanas. Segunda Entrega. Santiago de Chile: Imprenta Cervantes (= Los elementos indios del castellano de Chile. Estudio lingüístico i etnolójico. Primera parte).

1919. "Sobre el estudio de idiomas". Carta al señor Julio Saavedra Molina (y respuesta de Julio Saavedra). Santiago de Chile: Sociedad Imprenta i Litografía Barcelona.

1920. La oración y sus partes. Madrid: Centro de Estudios Históricos.

1926-1927. El papiamento. La lengua criolla de Curazao. La gramática más sencilla. Anales de la Universidad de Chile 4(2): 694-768; 1021-1090 (1926); 5(2): 288-327; 366-412; 888-989 (1927) [en línea]. Disponible en http://www.anales.uchile. cl/index.php/ANUC/article/viewFile/26693/28266, http:/www.anales.uchile.cl/index. php/ANUC/article/viewFile/26703/28273, http://www.anales.uchile.cl/index.php/ ANUC/article/viewFile/25444/26772, http:/www.anales.uchile.cl/index.php/ANUC/ article/viewFile/25449/26776, http://www.anales.uchile.cl/index.php/ANUC/article/ viewFile/25493/26821 (Consulta 28/05/2020).

1928. El papiamento. La lengua criolla de Curazao. La gramática más sencilla. Santiago: Imprenta Litografia Balcells \& Co.

Lichem, KLAUS Y WolfGang WÜRDINGER. 2013. Die Korrespondenz zwischen Graziadio Isaia Ascoli und Hugo Schuchardt. En Bernhard Hurch (ed.). Hugo Schuchardt Archiv [en línea]. Disponible en http://schuchardt.uni-graz.at/id/person/1056 (Consulta 28/05/2020).

Lindgren, Uta. 2001. Philippi, Bernhard Eunom. Neue Deutsche Biographie 20: 392 f. [en línea]. Disponible en http://www.deutsche-biographie.de/ppn117685410.html (Consulta 28/05/2020).

LóPez MendizÁBAL, IsAaC. 1916. Diccionario castellano-euzkera. Tolosa'n Lopez’tar E.'ren etxean.

Lyttkens, Ivar Adolf y Fredrik Amadeus WulfF. 1892. Metodiska ljudöfningar. Lund: C.W.K. Gleerup.

MaAs, Utz. 2010. Rodolfo (Rudolf) Lenz. En U. Maas. Verfolgung und Auswanderung deutschsprachiger Sprachforscher 1933-1945 [en línea]. Disponible en https://zflprojekte. de/sprachforscher-im-exil/index.php/catalog/1/310-lenz-rodolfo-rudolf (Consulta 28/05/2020). 
Maduro, Antoine J. 1967. Observacion i apuntenan tocante 'El Papiamento. La lengua criolla de Curazao', Santiago de Chile -1928 di Dr. Rodolfo Lenz. Curaçao: Antoine Maduro.

Markey, Thomas L. 1982. [Res. de] Lichem Klaus \& Hans-Joachim Simon, Hg., Hugo Schuchardt. Language 58: 683-686.

Meillet, Antoine. 1914. Le Problème de la parenté des langues. Scientia 15: 403-425.

MelChior, LuCA y JoHANnes MüCKe. 2013. Bausteine zur Rekonstruktion eines Netzwerks IV: Von Diez zur Sprachanthropologie. Grazer Linguistische Studien 80: 5-22.

Middendorf, ERnst Wilhelm. 1890. Die einheimischen Sprachen Perus. Band 1. Das Runa Simi oder die Keshua-Sprache, wie sie gegenwärtig in der Provinz Cuzco gesprochen wird. Leipzig: F. A. Brockhaus.

1891. Die einheimischen Sprachen Perus. Band 5. Die Aimara-Sprache. Leipzig: F. A. Brockhaus.

1892. Die einheimischen Sprachen Perus. Band 6. Das Muchik oder die ChimuSprache. Leipzig: F. A. Brockhaus.

MÜCKe, JohANnes. 2015a. “.... unsere freundschaftlichen Beziehungen...” Zum Verhältnis von Hermann Paul und Hugo Schuchardt. Grazer Linguistische Studien 80: 125-164.

2015b. Die Korrespondenz zwischen August Friedrich Pott und Hugo Schuchardt. En B. Hurch (ed.). Hugo Schuchardt Archiv [en línea]. Disponible en http://schuchardt. uni-graz.at/id/person/2438 (Consulta 25/06/2020).

Mücke, Johannes y Silvio Moreira De Sousa. 2015a. Die Korrespondenz zwischen Rodolfo Lenz und Hugo Schuchardt. En Bernhard Hurch (ed.). Hugo Schuchardt Archiv [en línea]. Disponible en http://schuchardt.uni-graz.at/id/person/2024 (Consulta 28/05/2020).

2015b. Hugo Schuchardt and his Network of Knowledge. History and Philosophy of the Language Sciences [en línea]. Disponible en https://hiphilangsci.net/2015/05/20/ hugo-schuchardt-netknowl (Consulta 28/05/2020).

NykL, Alois R. 1928. [Res. de] R. Lenz, El Papiamento, la lengua criolla de Curazao: la gramatica mas sencilla. The American Journal of Philology 49(4): 399-401 [en línea]. Disponible en: http://www.jstor.org/stable/290060 (Consulta 28/05/2020).

Putman, J. J. 1852. Bida di Hesoe Kriestoe. Santa Rosa.

1853a. Gemeenzame Zamenspraken, behoorende by de: Proeve eener Hollandsche Spraakkunst, ten gebruike der algemeene armenschool, in de gemeente van de H. Rosa, op Curaçao. Tweede stukje door J. J. Putman. Santa Rosa.

1853b. Meditasjon arieba soefrimeentoe di noos Senjoor Hesu Kriestoe. Historia, exemplo i orasjon, pa J. J. Putman, Pastoor; $i$ soe roeman, Joanna Adr. Putman, fundadora di skool pa moetsja moheer pober na Sta. Rosa. Imprimier na Santa Rosa.

1853c. Oen Floor, ki J. J. Putman ta boeta arieba sepoelkro di soe roeman stimaar Joanna Adriana Putman. Imprimier na Santa Rosa.

Rodríguez, Zorobabel. 1875. Diccionario de chilenismos. Santiago de Chile: Imprenta de "El Independiente" [en línea]. Disponible en: https://archive.org/details/ diccionariodechi00rodruoft (Consulta 28/05/2020).

Schuchardt, Hugo. 1882a. Kreolische Studien I. Ueber das Negerportugiesische von S. Thomé (Westafrika). Sitzungsberichte der philosophisch-historischen Classe der Kaiserlichen Akademie der Wissenschaften. Wien 101: 889-917 [en línea]. Disponible en http://schuchardt.uni-graz.at/id/publication/529 (Consulta 28/05/2020).

1882b. Kreolische Studien II. Ueber das Indoportugiesische von Cochim. Sitzungsberichte der philosophisch-historischen Classe der Kaiserlichen Akademie der Wissenschaften. Wien 102: 799-816 [en línea]. Disponible en http://schuchardt.uni-graz. at/id/publication/54 (Consulta 28/05/2020). 
1882c. Sur le créole de la Réunion. Romania 11: 589-593 [en línea]. Disponible en http://schuchardt.uni-graz.at/id/publication/454 (Consulta 28/05/2020).

1883. Kreolische Studien III. Ueber das Indoportugiesische von Diu. Sitzungsberichte der philosophisch-historischen Classe der Kaiserlichen Akademie der Wissenschaften. Wien 103: 3-18 [en línea]. Disponible en http://schuchardt.uni-graz.at/id/publication/772 (Consulta 28/05/2020).

1884a. Kreolische Studien IV. Ueber das Malaiospanische der Philippinen. Sitzungsberichte der philosophisch-historischen Classe der Kaiserlichen Akademie der Wissenschaften. Wien 105: 111-150 [en línea]. Disponible en http://schuchardt.uni-graz. at/id/publication/766 (Consulta 28/05/2020).

1884b. Kreolische Studien V. Ueber das Melaneso-englische. Sitzungsberichte der philosophisch-historischen Classe der Kaiserlichen Akademie der Wissenschaften. Wien 105: 151-161 [en línea]. Disponible en http://schuchardt.uni-graz.at/id/publication/617 (Consulta 28/05/2020).

$1884 \mathrm{c}$. Kreolische Studien VI. Ueber das Indoportugiesische von Mangalore. Sitzungsberichte der philosophisch-historischen Classe der Kaiserlichen Akademie der Wissenschaften. Wien 105: 882-904 [en línea]. Disponible en http://schuchardt.uni-graz. at/id/publication/299 (Consulta 28/05/2020).

1886. [Res. de] Otto Jespersen, Til spörgsmålet om lydlove; Jakob Hornemann Bredsdorff, Om Aarsagerne til Sprogenes Forandringer. Paa ny udgivet af Vilh. Thomsen. Deutsche Literaturzeitung 7: 1557-1559 [en línea]. Disponible en http://schuchardt.unigraz.at/id/publication/548 (Consulta 28/05/2020).

1888a. Beiträge zur Kenntnis des kreolischen Romanisch I. Allgemeineres über das Negerportugiesische. Zeitschrift für romanische Philologie 12: 242-254 [en línea]. Disponible en http://schuchardt.uni-graz.at/id/publication/752 (Consulta 28/05/2020).

1888b. Beiträge zur Kenntnis des kreolischen Romanisch II. Zum Negerportugiesischen Senegambiens. Zeitschrift für romanische Philologie 12: 301312 [en línea]. Disponible en http://schuchardt.uni-graz.at/id/publication/370 (Consulta 28/05/2020).

1888c. Beiträge zur Kenntnis des kreolischen Romanisch III. Zum Negerportugiesischen der Kapverden. Zeitschrift für romanische Philologie 12: 312322 [en línea]. Disponible en http://schuchardt.uni-graz.at/id/publication/386 (Consulta 28/05/2020).

1888d. Kreolische Studien VII. Ueber das Negerportugiesische von Annobom. Sitzungsberichte der philosophisch-historischen Classe der Kaiserlichen Akademie der Wissenschaften. Wien 116: 193-226 [en línea]. Disponible en http://schuchardt.uni-graz. at/id/publication/302 (Consulta 28/05/2020).

1888e. Kreolische Studien VIII. Ueber das Annamito-französische. Sitzungsberichte der philosophisch-historischen Classe der Kaiserlichen Akademie der Wissenschaften. Wien 116: 227-234 [en línea]. Disponible en http://schuchardt.uni-graz.at/id/publication/2 (Consulta 28/05/2020).

1889a. Beiträge zur Kenntnis des kreolischen Romanisch IV. Zum Negerportugiesischen der Ilha do Principe. Zeitschrift für romanische Philologie 13: 464-475 [en línea]. Disponible en http://schuchardt.uni-graz.at/id/publication/780 (Consulta 28/05/2020).

1889b. Beiträge zur Kenntnis des kreolischen Romanisch V. Allgemeineres über das Indoportugiesische (Asioportugiesische). Zeitschrift für romanische Philologie 13: 476-516 [en línea]. Disponible en http://schuchardt.uni-graz.at/id/publication/776 (Consulta 28/05/2020). 
1889c. Beiträge zur Kenntnis des kreolischen Romanisch VI. Zum Indoportugiesischen von Mahé und Cannanore. Zeitschrift für romanische Philologie 13: 516-524 [en línea]. Disponible en http://schuchardt.uni-graz.at/id/publication/20 (Consulta 28/05/2020).

1890. Kreolische Studien IX. Ueber das Malaioportugiesische von Batavia und Tugu. Sitzungsberichte der philosophisch-historischen Classe der Kaiserlichen Akademie der Wissenschaften. Wien 122: 1-256 [en línea]. Disponible en http://schuchardt.uni-graz. at/id/publication/176 (Consulta 28/05/2020).

1892. [Res. de] Fredrik Wulff. Un chapitre de phonétique avec transcription d'un texte andalou; Von der Rolle des Akzentes in der Versbildung. Literaturblatt für germanische und romanische Philologie 13: 235-246 [en línea]. Disponible en http:// schuchardt.uni-graz.at/id/publication/10 (Consulta 28/05/2020).

1909. Die Lingua franca. Zeitschrift für romanische Philologie 33: 441-461 [en línea]. Disponible en http://schuchardt.uni-graz.at/id/publication/409 (Consulta 28/05/2020).

1914a. Die Sprache der Saramakkaneger in Surinam. Amsterdam: Johannes Müller. (= Verhandelingen der Koninklijke Akademie van Wetenschappen te Amsterdam. Afdeeling Letterkunde. Nieuwe Reeks. Deel XIV (6). [en línea]. Disponible en http:// schuchardt.uni-graz.at/id/publication/634 (Consulta 28/05/2020).

1914b. Zur methodischen Erforschung der Sprachverwandtschaft II. Revista Internacional de Estudios Vascos / Revue International des Études Basques 8: 389-396 [1-8] [en línea]. Disponible en http://schuchardt.uni-graz.at/id/publication/58 (Consulta 28/05/2020).

1925a. Das Baskische und die Sprachwissenschaft. Viena: Hölder-Pilcher-Tempsky [en línea]. Disponible en http://schuchardt.uni-graz.at/id/publication/6 (Consulta 28/05/2020).

1925b. Der Individualismus in der Sprachforschung. Sitzungsberichte der Akademie der Wissenschaften in Wien. Philosophisch-historische Klasse 204(2): 1-21 [en línea]. Disponible en http://schuchardt.uni-graz.at/id/publication/667 (Consulta 28/05/2020).

Schütz, Günther. 1976. Epistolario de Rufino José Cuervo con filólogos de Alemania, Austria y Suiza. Y noticias de las demas relaciones de Cuervo con estos paises y sus representantes. 2 volumes. Bogotá: Publicaciones del Intituto Caro y Cuervo (= Archivo Epistolar Colombiano 8, 9).

SchwÄGerl-Melchior, Verena. 2016. Bausteine zur Rekonstruktion eines Netzwerks V: Die Objektsammlung Hugo Schuchardts im Netzwerk des Wissens. Grazer Linguistische Studien 85: 5-23 [en línea]. Disponible en http://unipub.uni-graz.at/gls/periodical/ titleinfo/1572701 (Consulta 28/05/2020).

Seifert, Eva. 1933. [Res. de:] Rodolfo Lenz, El Papiamento, la lengua criolla de Curazao, Anales de la Universidad de Chile, 2a serie, año IV, 1926 y V, 1927, Establecimientos gráficos "Balcells \& Co.", Santiago de Chile, 1928. Zeitschrift für romanische Philologie 53: 413-414 [en línea]. Disponible en http://gallica.bnf.fr/ark:/12148/bpt6k15903w/f417. image (Consulta 28/05/2020).

Sousa, Silvio MoreIRa DE. 2013. Die Korrespondenz zwischen Francisco Adolfo Coelho und Hugo Schuchardt. En B. Hurch (ed.). Hugo Schuchardt Archiv [en línea]. Disponible en http://schuchardt.uni-graz.at/id/person/1317 (Consulta 28/05/2020).

Sousa, Silvio Moreira de, y Johannes Mücke. 2016. Networking and obstacles to the development of the language sciences as reflected in the correspondence of Rodolfo Lenz and Hugo Schuchardt. History and Philosophy of the Language Sciences [en línea]. Disponible en https://hiphilangsci.net/2016/02/17/networking-and-the-obstacles-to-thedevelopment-of-the-language-sciences (Consulta 28/05/2020).

Tagliavini, Carlo. 1968. Panorama di storia della linguistica. Bologna: R. Patron. 
Wagner, Max L. 1931. '[Res. de:] Rodolfo Lenz - El Papiamento. La lengua criolla de Curazao. La gramática más sencilla. Revista de Filología Española 18(3): 284-286.

WallensKöLd, A. 1929. [Res. de:] El Papiamento, la lengua criolla de Curazao by Rodolfo Lenz. Neuphilologische Mitteilungen 30(1-2): 86-87 [en línea]. Disponible en http://www. jstor.org/stable/43345639 (Consulta 28/05/2020).

Weiss, BrigitTa. 1981. Hugo Schuchardt y el mundo hispánico. Thesaurus. Boletín del Instituto Caro y Cuervo 36(2): 205-229.

Weiss, BrigitTa. 1984. Otros autógrafos de Rufino José Cuervo en la Universitätsbibliothek de Graz. Thesaurus. Boletín del Instituto Caro y Cuervo 39: 1-45.

${ }^{3}$ 1986a. Katalog der Schuchardt-Bibliothek. Graz (= Universitätsbibliothek Graz, Bibliographische Informationen 6).

1986b. 'Cuervo y Schuchardt. I. Otras dos cartas de Cuervo a Schuchardt'. Thesaurus. Boletin del Instituto Caro y Cuervo 41: 120-124.

WinkLer, HeInRICH. 1921. Die Altaische Völker- und Sprachenwelt. Leipzig: Teubner.

Wolf, Michaela. 1993. Der Hugo Schuchardt Nachlaß. Schlüssel zum Nachlaß des Linguisten und Romanisten Hugo Schuchardt (1842-1927). Graz: Leykam.

WulfF, Fredrik Amadeus. 1889. Un chapitre de phonétique avec transcription d'un texte andalou. Stockholm: L'imprimerie centrale.

1891. Von der Rolle des Akzentes in der Versbildung. Skandinavisches Archiv 1(1): 59-90.

Zirnstein, Gottrried. 2001. Rudolf Amandus Philippi. En Neue Deutsche Biographie 20: $391 \mathrm{f}$. [en línea]. Disponible en http://www.deutsche-biographie.de/ppn116174536.html (Consulta 28/05/2020). 